\title{
Light Water Reactor Sustainability (LWRS) 2017 Accomplishments Report
}

\author{
B.P. Hallbert
}

March 2018

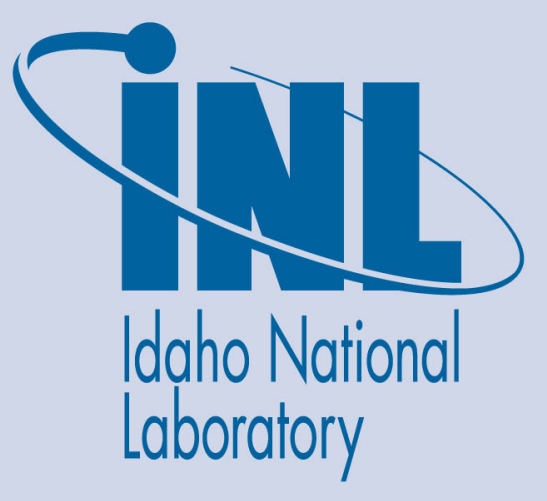

The INL is a U.S. Department of Energy National Laboratory operated by Battelle Energy Alliance 


\title{
Light Water Reactor Sustainability (LWRS) 2017 Accomplishments Report
}

\author{
B.P. Hallbert \\ March 2018 \\ Idaho National Laboratory \\ Idaho Falls, Idaho 83415 \\ http://www.inl.gov \\ Prepared for the \\ U.S. Department of Energy \\ Under DOE Idaho Operations Office \\ Contract DE-AC07-05ID14517
}




\section{LWRS}

LIGHT WATER REACTOR SUSTAINABILITY

\section{Accomplishments Report}

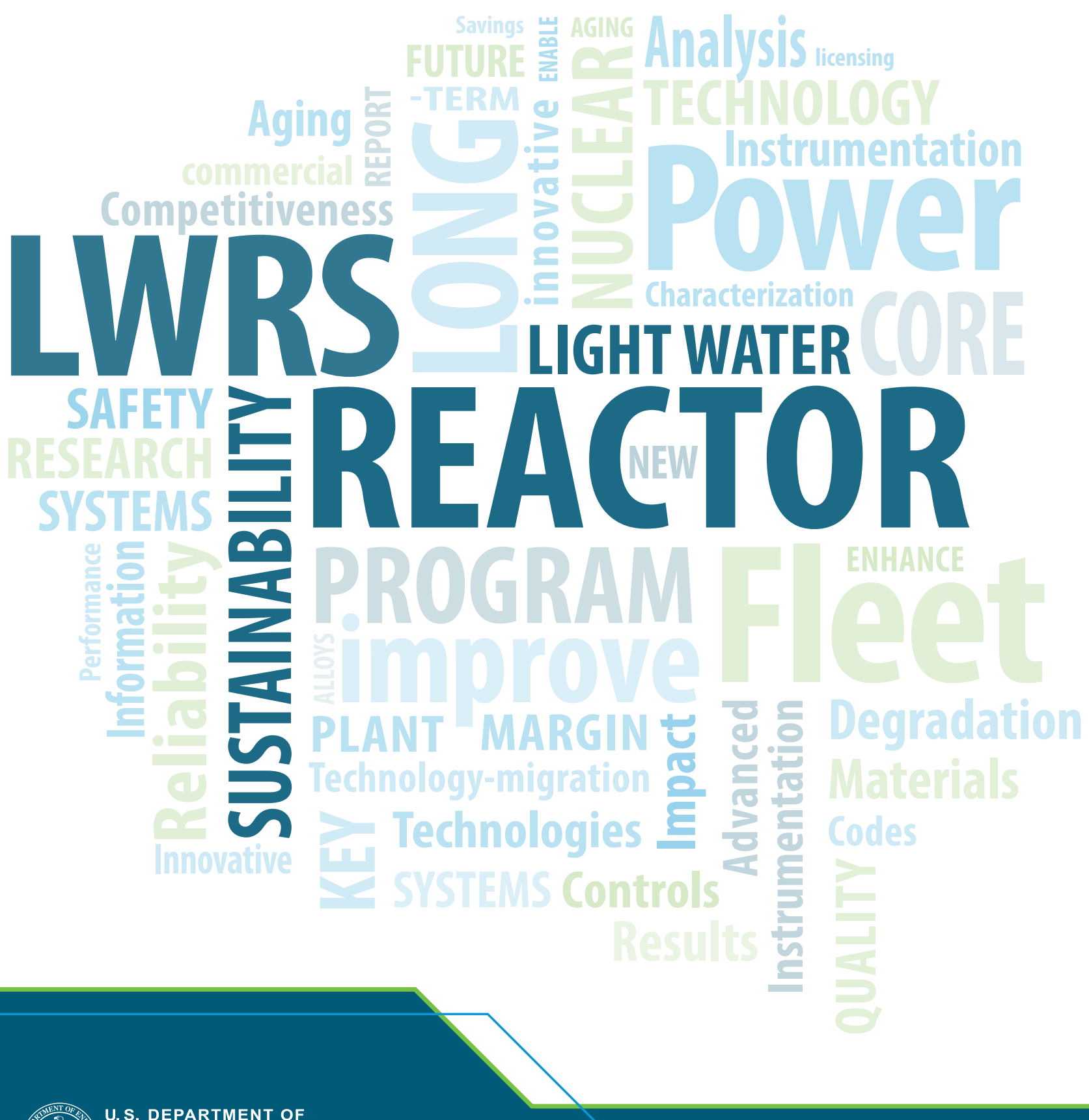




\section{From the LWRS Program Technical Integration Office Director}

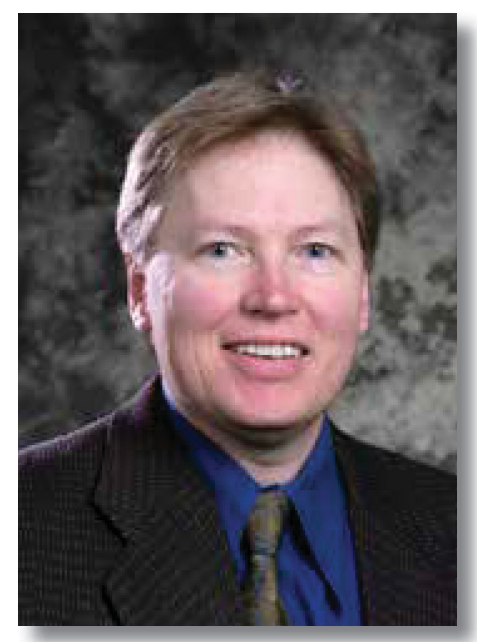

Bruce Hallbert, Director, LWRS Program Technical Integration Office.

\author{
A elcome to the Light Water Reactor \\ Sustainability (LWRS) Program's 2017 Annual \\ Accomplishments report. It's my pleasure
} to introduce the results and accomplishments of the research and partnerships that have led to this year's many noteworthy outcomes. This program represents a collection of efforts focused on ensuring the continued safe, reliable, and economic performance of our nation's commercial nuclear power reactors. This requires the program to have a focus both on the long term - where performance of materials can become life limiting issues for continued plant operations - while also working to effect the ability of nuclear power plants to be economically viable and competitive in the electricity markets today and in the near term.

These challenges set the stage for our ongoing interactions with the many stakeholders of the

LWRS Program, including our research partners and the fleet of owner-operators representing the commercial U.S. nuclear power industry. It is vital to our program that just as the commercial nuclear power fleet addresses factors needed to ensure its longevity, that the LWRS Program is informed by these decisions and is able to structure its activities to ensure the availability of data from research projects, technical bases that can be used to support continued operations, and technology innovations that will enable new approaches to operations to reach suppliers and owner-operators in a timely manner.

This year's cover features a new design to introduce the topics discussed in this year's accomplishments report: a word cloud. The word cloud provides a visual summary of the key terms that you'll find in this year's report. The cloud shows that the LWRS Program's activities focus on sustaining nuclear power plants through research and development. Across the four pathways of research: Materials Aging and Degradation; Advanced Instrumentation, Information, and Controls Systems Technologies; RiskInformed Safety Margin Characterization; and Reactor Safety Technologies a number of significant outcomes and accomplishments are summarized that demonstrate the progress made in the LWRS Program toward supporting the long-term operation of the U.S. commercial nuclear power industry.

The LWRS Program is building on these and other accomplishments and experience gained through its research that has and will support continued safe plant operation during continued periods of plant licenses. The LWRS Program continues to demonstrate and provide innovative methods and technologies that are needed by the U.S. fleet of light water reactor owner-operators and their suppliers to enable continuous improvement needed for extended operation. I hope that this accomplishments report provides you with valuable information that you and 
others can use to learn about the different research and development projects that constitute our program. Looking ahead to the future, we would always like to hear from you to better understand industry interests and priorities, and to answer any questions about the information in the report or about the LWRS Program. Please contact myself or Alison Hahn, our Department of Energy Federal Program Manager, or the respective research pathway leader (noted on pages 42 or 43). Further information about the LWRS Program and more technical information in the areas covered in this accomplishments report can also be found on the LWRS Program website (https://lwrs.inl.gov).

- he mission of the Light Water Reactor Sustainability Program is development of the scientific basis, and science-based methodologies and tools, for the safe and economical long-term operation of the nation's high-performing fleet of commercial nuclear power plants.

\section{Contents}

Introduction

2017 Research Highlights

Materials Aging and Degradation .......................................................................................6

Advanced Instrumentation, Information and Control Systems Technologies ............20

Risk-informed Safety Margin Characterization ...............................................................30

Reactor Safety Technologies ...................................................................................................38

\section{On the Cover}

This year's cover features a word cloud providing a visual summary of the key terms in the report, showing that the LWRS Program's activities focus on sustaining nuclear power plants through research related activities.

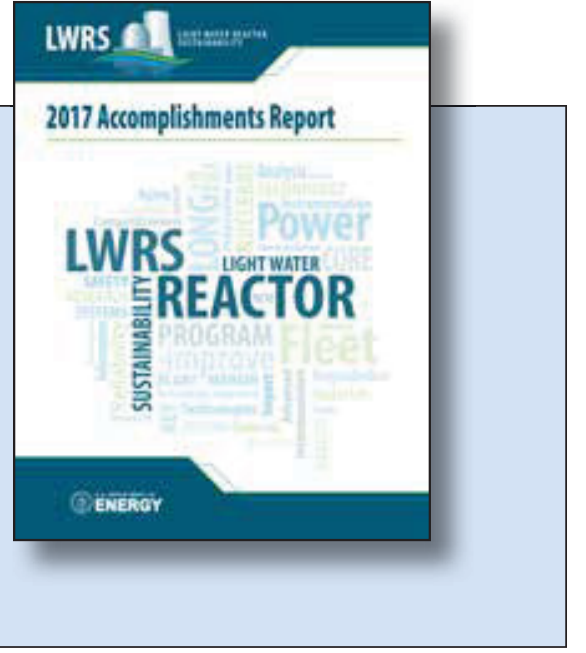




\section{INTRODUCTION}

he U.S. Department of Energy's Light Water Reactor Sustainability (LWRS) Program is the Office of Nuclear Energy's primary research and development program carried out to support the continued safe, reliable, and economic operation of the nation's fleet of commercial nuclear power plants. Many of our nation's nuclear power plants have applied for and received permission to continue licensed power operations through license renewal extending their initial operating license period out to 60 years. Recently, several utilities have announced that they plan to submit applications to the U.S. Nuclear Regulatory Commission to begin the subsequent license renewal process extending the operating license period beyond 60 years from the date of their initial licensing. This marks an important planned milestone in the history of commercial nuclear power operations in the United States - one that underscores the long-term dependability of these plant designs and the commitment to their long-term performance by the organizations that operate them. It also demonstrates the value of the previous eight years of research that has been jointly conducted and coordinated between the U.S. Department of Energy and its industrial partners, especially the Electric Power Research Institute, together with many universities and international organizations, to address the key issues needed to support the technical bases for continued safe long-term operation of our nation's nuclear power assets.

Research by the LWRS Program continued its strong record of accomplishments in 2017, producing data and other technical results that are needed and used by nuclear power plant owner-operators, regulators, and other stakeholders to inform a variety of decisions. This includes producing results from research on in-service performance of key materials under extended service conditions to ensure that commercial nuclear power plants can be safely and reliably operated for periods up to 80 years. Data from recent sponsored research indicates that the brittle fracture temperature of reactor pressure vessel steels will be manageable for a majority of the U.S. pressurized water reactor fleet, based upon a recently completed materials irradiation campaign conducted at the Department of Energy's Advanced Test Reactor at the Idaho National Laboratory.

The LWRS Program's research was featured as a cover story in the June 2017 edition of Nuclear News (Figure 1) for the leading-edge research and development activities that this Program's funded research has helped to facilitate with first movers in the commercial nuclear power industry to modernize their main control rooms. Confronting the challenges of aging analog instrumentation replacement is an industry-wide issue that poses technical, regulatory, and financial uncertainties. Capabilities developed through this Program continued to demonstrate the means to address viable approaches to address these issues through efforts conducted with key stakeholders.

The LWRS Program also made significant progress in 2017 towards advancing the state of the art in risk informed codes and tools for margins management of commercial nuclear power plants. A family of new codes and tools will enable plants to couple thermal-hydraulic, probabilistic risk assessment, and other engineering codes within a seamless framework for analyzing plant hazards to better estimate the sources of risk and manage them without incorporating unnecessary conservatisms and sources of 
uncertainty into their results. The results and estimates produced from these analyses will help plants to effectively recover margins that are often lost through conservative analyses and accumulated uncertainty propagation when results are passed between traditional engineering codes. These features were demonstrated through a first of a kind pilot of the technology with a participating utility.

The LWRS Program continued research and development efforts with industry to help improve understanding of beyond design basis events in the wake of the March 2011 events at Fukushima Daiichi in Japan. Research from the LWRS Program together with data and insights from the accidents in Japan are being used to improve knowledge of severe accident phenomenology, analytical codes used for modeling accident progression, and to aid the U.S. industry in developing improved mitigating strategies and guidelines for managing severe accidents for the current light water reactor fleet.

As it looks to the future, the LWRS program will be informed by the operating experience from the current fleet of operating plants including factors affecting utility economic performance and future viability in the nation's electricity markets. The results of this year's accomplishments are already being taken into use within the industry and having an impact on decisions that support long-term operation. In the coming year, we look forward to continuing this trend by identifying opportunities to increase the deployment of research results from this program to sustain the operating fleet of US nuclear power reactors.
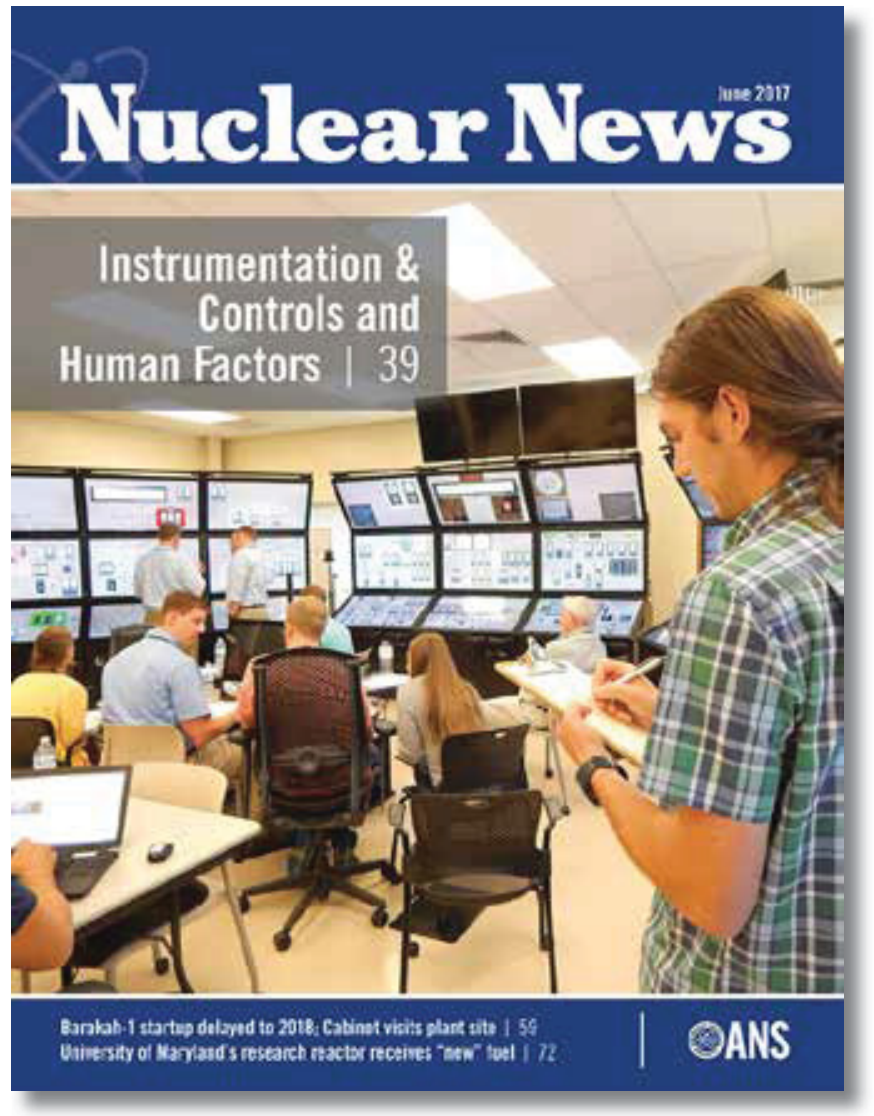

Figure 1. Nuclear News June 2017 cover with photograph of research in the LWRS Programsponsored Human-Systems Simulation Laboratory. 


\section{RESEARCH HIGHLIGHTS}

\section{Materials Aging and Degradation Pathway}

Materials research provides an important foundation for licensing and managing the long-term, safe, and economical operation of nuclear power plants. Aging mechanisms and their influence on nuclear power plant systems, structures and components are predictable with sufficient confidence to support planning, investment, and licensing for necessary component repair, replacement, and relicensing. Understanding, controlling, and mitigating materials degradation processes are key priorities. The strategic goals of the Materials Aging and Degradation pathway are to develop the scientific basis for understanding and predicting long-term environmental degradation behavior of materials in nuclear power plants and to provide data and methods to assess performance of systems, structures, and components essential to safe and economically sustainable nuclear power plant operations. This includes methods for monitoring and measuring degradation, to understand the aging mechanisms and to model materials and component performance towards developing strategies to mitigate the effects of aging.

\section{Research Highlights}

Select research and development highlights are provide here. Detailed reports covering the accomplishments can be found on the LWRS Program website (https:// Iwrs.inl.gov).

\section{Predictive Modeling Approaches to Reactor Pressure Vessel Steel Performance}

Understanding the effects of long-term operation on materials, such as reactor pressure vessel (RPV) steels is a primary goal of the Materials Aging and Degradation Pathway. Limited data at high fluences, for long service times, and for specific alloy chemistries create uncertainties for RPV embrittlement predictions. Furthermore, current regulatory models under predict high-fluence embrittlement, measured in accelerated test reactor studies, as they do not reflect the changes in microstructure that influence mechanical properties during extended vessel operation. To address these issues, the LWRS Program is taking a multi-directional approach that involves mechanistic modeling of processes influencing RPV performance, machine learning and fitting models for database evaluation, all coupled to an ambitious experimental research effort.

\section{Experimental Database Development and Advanced Steels}

The ATR-2 experiment, bridges gaps between previous experimental datasets and expands the overall mechanical and microstructural database for RPV steels. The project involves the irradiation and characterization of 172 alloys that systematically vary in composition that includes materials used in commercial surveillance programs and a subset of advanced alloy steels developed by Rolls Royce. To date, 52 tensile, 110 microhardness, 141 shear punch tests have been completed and complimented by microstructural characterization of 28 atom probe tomography, 69 small angle neutron scattering, 89 X-ray diffraction, and 86 small angle $X$-ray scattering measurements have been accomplished. The experimental data collected provides information on the development of the $\mathrm{Mn}-\mathrm{Ni}-\mathrm{Si}$ 
precipitates (MNSPs) that form at high fluences, so called "late blooming" phases, and their dependence on irradiation condition and alloy composition.

During 2017, research was conducted on a new class of advanced steels developed by Rolls Royce and incorporated into the ATR-2 experiment. While increased Ni content in RPV steels has the benefit of improving the unirradiated strength and toughness, it results in increased propensity for embrittlement from irradiation due the increased volume fraction of MNSPs developed. However, if the Mn content is reduced using low sulfur, super clean steel technology, a class of very high $3.5 \% \mathrm{Ni}$ steels (nearly more than five times that in most U.S. RPV steels) could be possible for use in nuclear environments. It has been demonstrated in the ATR-2 experimental work that the high $\mathrm{Ni}$, reduced $\mathrm{Mn}$, steel produces no significant increase in hardening compared to steels with normal Mn levels and low to medium Ni concentrations (Figure 2). While further evaluation of the advanced steels is being conducted for different irradiation conditions, the preliminary results are favorable and could represent a technological advance for new reactor constructions. The LWRS program primarily uses these results to provide an important understanding to the formation of $\mathrm{Mn}-\mathrm{Ni}$-Si or "late blooming" phases and ensure the validity of the models currently being developed.

\section{Experimental Database Fitting Model}

An Avrami-type fitting model combined with a formation-transformation model to account for the solute-defect clusters produced in the radiation damage cascades, has been applied to the experimental datasets to track the evolution of the precipitates with fluence. The fitted model for the volume fraction change of precipitates with fluence can be quantitatively linked to changes in mechanical properties (i.e., tensile, microhardness, shear strength) through a well-established and validated superposition model to provide transition temperature shift curves as a function of fluence for specific alloy types. An example of the transition temperature shifts for
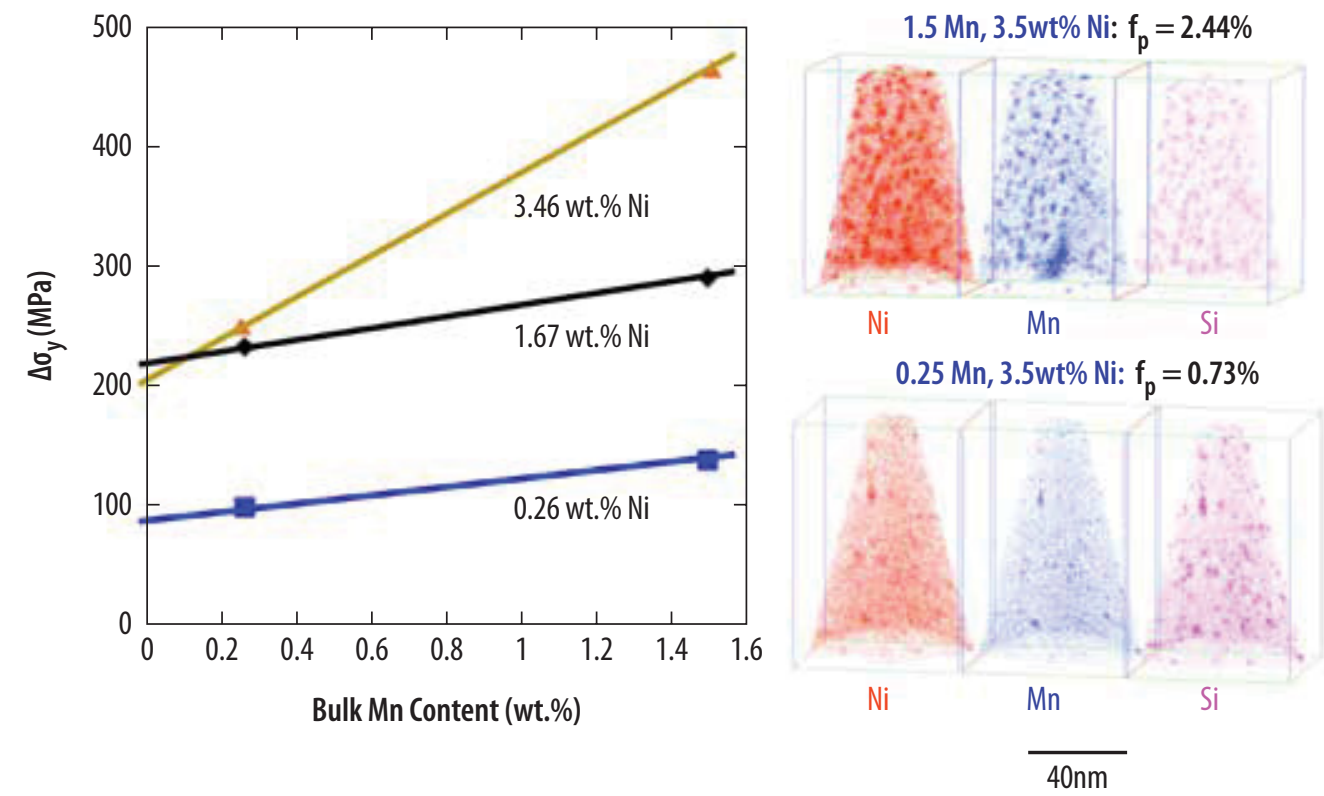

Figure 2. Comparison of the effect of Ni and Mn content on the MNSP development and hardening of irradiated RPV alloys. The atom probe tomography images (right) show the decrease in volume fraction of precipitates ( $f p$ ) when Mn solute content is reduced, resulting in a decrease in hardening $(\Delta \sigma y)$ of the alloy. 
Figure 3. The comparison of the Avrami, EONY and E900 models for transition temperature shift versus effective fluence of $a$ (left) low Cu, medium Ni alloy, and (right) high $\mathrm{Cu}$, medium Ni alloy. The hardening effect of stable matrix features developed from radiationinduced displacement cascades have not been incorporated into the Avrami model for the low Cu alloy.
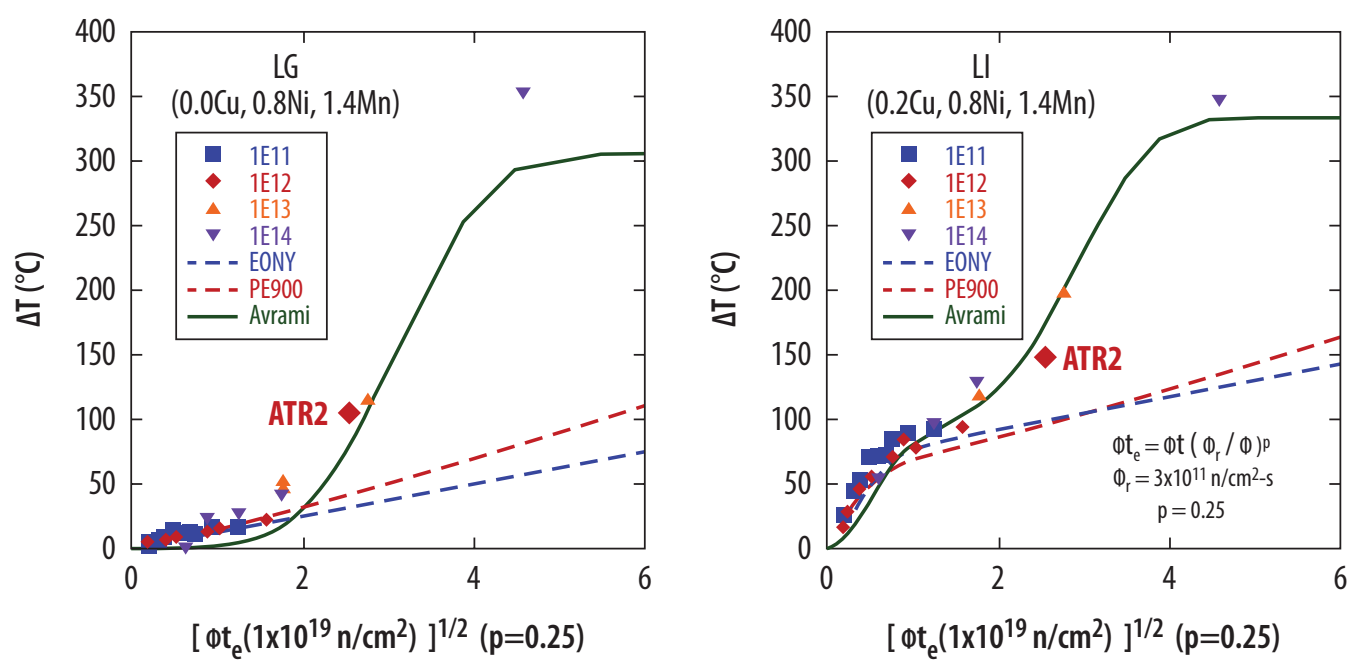

two RPV steel compositions derived from the experimental testing conducted this year is provided in Figure 3. The Avrami model shows closer matching of high fluence mechanical properties than that of the current regulatory Eason, Odette, Nanstad and Yamamoto (EONY) and E900 models.

\section{Mechanistic Model Development for RPV Embrittlement}

The rapidly expanding experimental datasets provide benchmarking modeling approaches taken by LWRS Program researchers for the prediction of RPV steel performance at high fluence. Researchers have developed a Molecular-scale Kinetic Monte Carlo (KMC) to simulate the mechanisms behind the nucleation and growth of the precipitates during the aging of RPV steel. The model provides insight into how the Cu-rich precipitates (formed early in the RPV life) catalyze the slower growing MNSPs and the mechanisms responsible for the appendage-like growth observed of the particles at higher fluences (Figure 4).

In addition to providing preliminary information on the stability of these precipitates, and the feasibility for mitigation treatments such as annealing, the KMC model is used to inform the higher-level meso-scale model. That model developed through Cluster Dynamics simulations, mechanistically predicts the extent of precipitation (amount, size of particles, etc.) as a function of radiation environment and alloy composition. When coupled to established structure - property correlations, transition temperature shifts as a function of alloy composition can be computed for a wide variety of materials and irradiation conditions. The accomplishments of this model are illustrated in the simplified transition temperature plot shown in Figure 5 for three generic levels of RPV alloy solute content. The information developed from the Cluster Dynamics modeling is now being incorporated into the multi-physics Grizzly platform to provide a holistic assessment of the RPV performance and risk assessment for fracture during the life of a plant. 


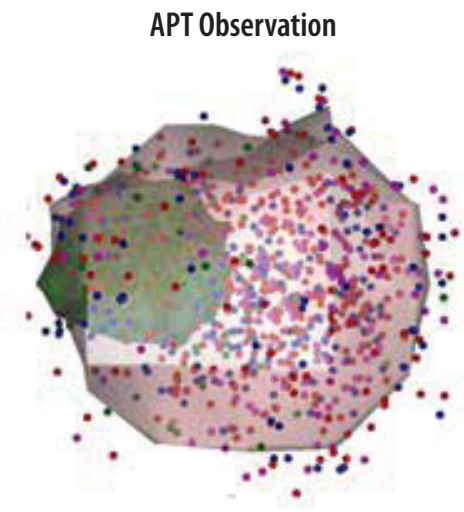

KMC Reproduction
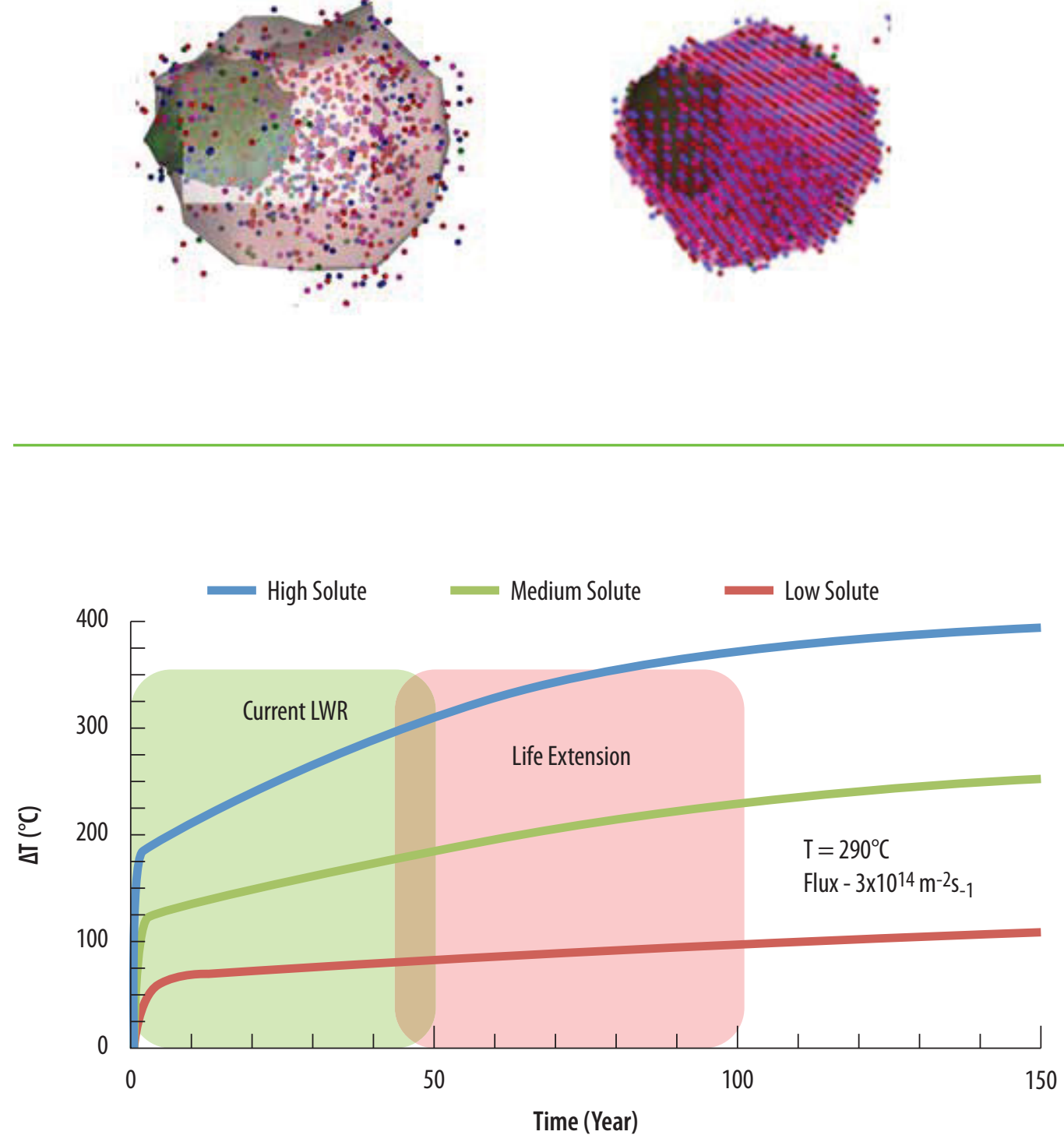

\section{Machine Learning Model}

A machine learning approach (specifically, Gaussian Kernel Ridge Regression method) was used to directly predict hardening as a function of alloy composition and irradiation conditions through mining existing database information. The machine learning model was trained to a portion of a database of over 1,500 measurements from more than 60 steel compositions, covering a wide-range of flux, fluence, and
Figure 4. Experimental atom probe tomography (APT) and Kinetic Monte Carlo (KMC) simulation showing appendage growth mechanism of Mn-Ni-Si on Cu precipitates.

Figure 5. Results of cluster dynamic simulations coupled to semi-empirical model data for the shift in transition temperature of RPV steels of generalized compositions showing the high dependence on solute content on long term performance. 
Figure 6. Comparison of machine learning versus experimental data for $R P V$ alloys tested in the ATR-2 experiment.

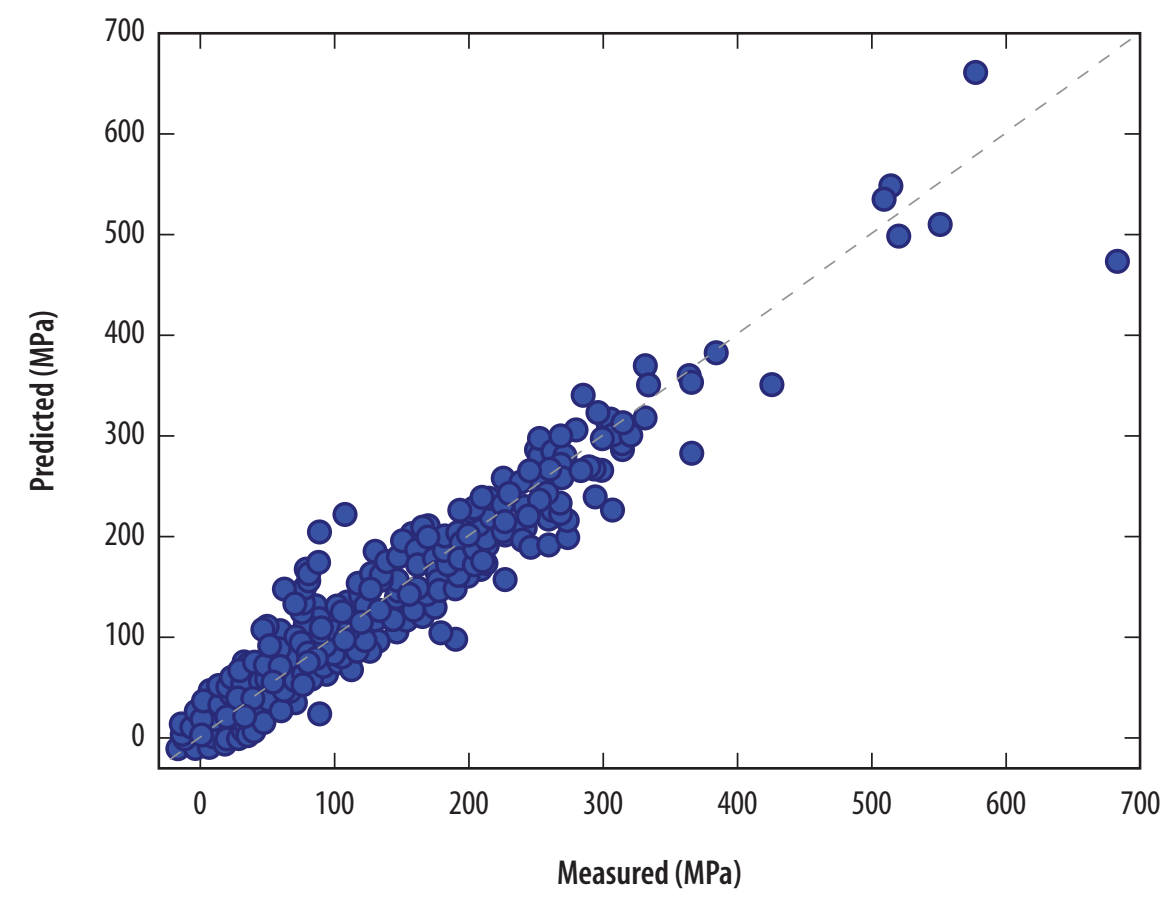

temperature. Figure 6 shows the comparison between the predicted alloy hardening data, purposefully left out of the database from which the machine learning model was trained from, and that of the experimentally derived data. The root mean squared error in the radiation-induced hardening data of about $20 \mathrm{MPa}$ is similar to the experimental uncertainty in the measurements taken. The machine learning model can provide excellent predictive capability for alloys and conditions similar to those in the database.

\section{Capabilities of RPV Models}

While the present models have yielded important insights and capability to predict precipitation and embrittlement of RPV steels, further improvements in the model physics and fitting are required to make the models complete, reliable and quantitatively accurate for low flux, high-fluence conditions. The modeling work accomplished this year provides the fundamental basis to develop a rigorous, quantitative, multiscale- and multi-physics model that supports the interpolation and extrapolation of embrittlement data for extended-life operation of the highly diverse fleet of U.S. RPVs.

To date, experimental and theoretical research conducted through the LWRS Program shows that while late blooming MNSP's will make a significant contribution to RPV embrittlement for extended life conditions, their absolute contributions to the shift in transition temperature (a measure of embrittlement) will be manageable for a majority of vessels in the U.S. pressurized water reactor fleet for extended life operations, due to the lower Ni and Cu contents of most RPV steels. 


\section{Model Code Development for Radiation-Induced Swelling of Core Internals}

The development of a validated model for radiation-induced swelling of metallic components at high fluence is an important step in estimating the useful life of core internal components. Understanding which components are susceptible to this form of degradation and under what conditions is of value to industry and regulators, as it will permit more focused component inspections, replacements, and improved regulatory guidelines.

The Radiation Induced Microstructural Evolution (RIME) code, is a modern, mean field, cluster dynamics model developed to investigate the materials and irradiation parameters that control swelling and microstructural evolution under the exposure conditions that are representative of the LWR core-operating environment. The RIME code was developed to evaluate swelling in austenitic stainless steel, and provides a unique capability in treating the incubation period of void swelling in irradiated materials. Furthermore, the RIME code provides an accurate understanding of the role of precipitates and dislocations on the screening of mobile self-interstitial atom clusters, along with the effective treatment of defect development, gas evolution and the dependence of residual gas in the material prior to irradiation. This makes the RIME code a far more effective model in identifying the duration of the nucleation stage and the transition to steady state swelling, at which point the material may surpass its engineering limits.

While much of the experimental data on swelling is from fast reactor tests, the RIME code has been further evaluated against experimental data from low flux components in advanced reactors as well as from data on LWR components. In all cases, the RIME code provides good correlation to experimental data, based on correct application of the materials and irradiation conditions to the code. Figure 7 shows an example of experimental results demonstrating the dose dependence of swelling and temperature in samples of 316 stainless steel.

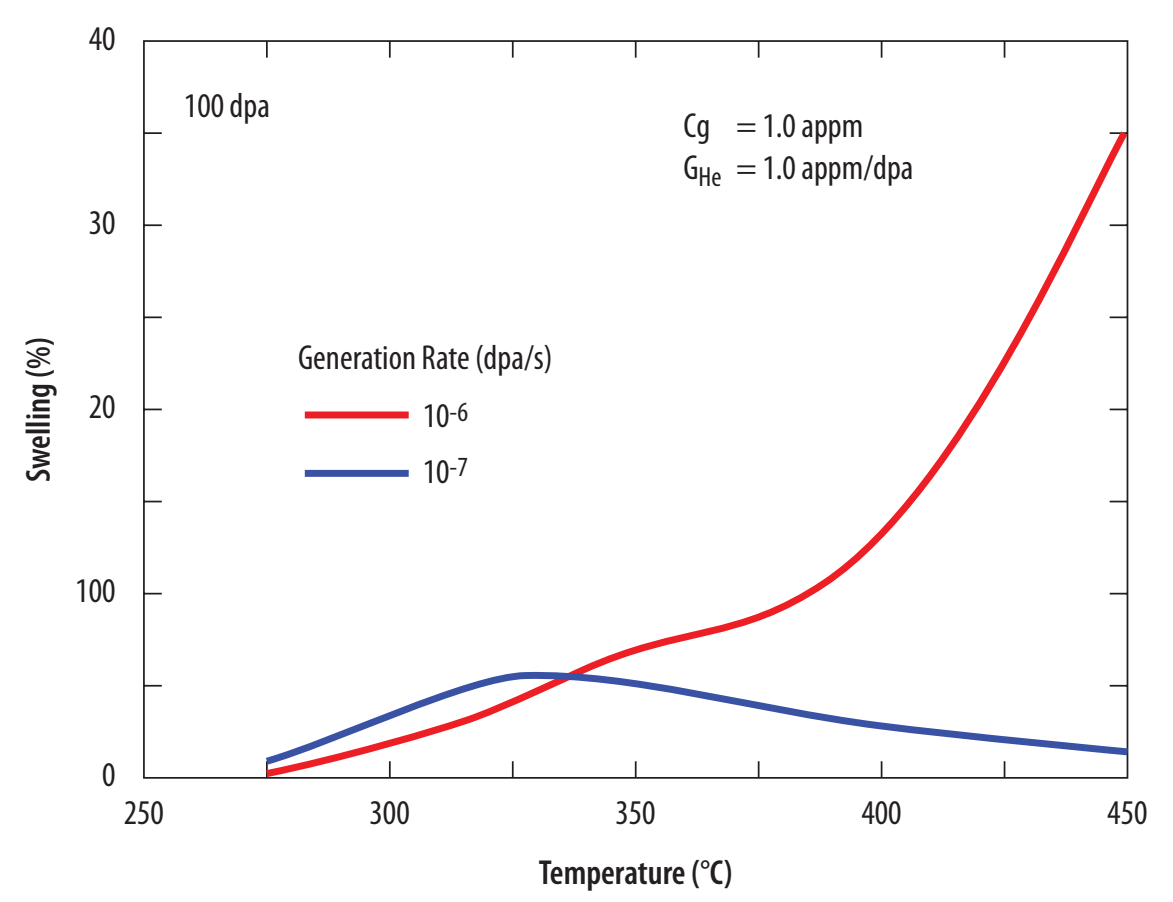

Figure 7. Comparison of the dose dependence of swelling versus temperature calculated for 316 stainless steel for 100 dpa irradiation, assuming residual gas concentration equal to $1 \mathrm{appm}$ and helium generation rates of 1 appm/dpa. 
Figure 8. Property ranking of (a) 7 low-strength and (b) 6 highstrength alloys on a 0 to 5 scale of best to worst.
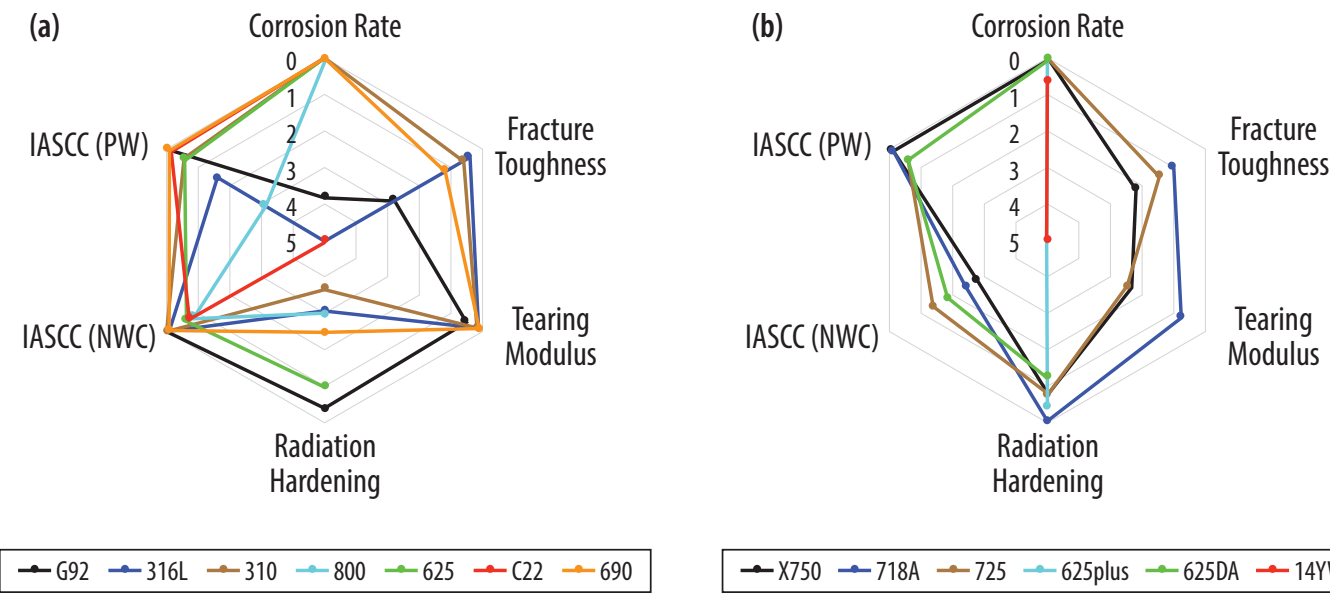

$\rightarrow X 750 \rightarrow 718 \mathrm{~A} \rightarrow 725 \rightarrow 625$ plus $\rightarrow$ 625DA $\rightarrow$ 14YWT

\section{Down-selection Process for Advanced Alloy Development Towards Improved Plant Economics}

The development of advanced alloys for use in LWR applications is part of the longterm planning of the LWRS Program to produce improved economics for current fleet operation and potential cost savings for new plant constructions. Improved materials performance over current alloy $316 \mathrm{~L}$ stainless steel and Ni-base alloy X-750 in use, provides expanded safety margins, offering flexibility in design and reduced inspection costs. In a collaborative effort with the Electric Power Research Institute, the Advanced Radiation Resistant Materials (ARRM) project seeks to support industry in developing advanced alloys by 2024.

Numerous alloys were evaluated at the initiation of the ARRM project for properties that are favorable for LWR core internal applications, leading to the initial selection of 15 alloys for Phase I testing. Key engineering properties of corrosion resistance, mechanical properties including fracture toughness, radiation resistance and irradiation assisted stress corrosion cracking (IASCC) susceptibility were evaluated for these alloys compared to 316 and X-750. Data collection and analysis of the initial screening that constituted Phase I activities of the ARRM project was completed in 2017.

An assessment of the alloys and their relative performance under testing were normalized to the 0-5 scale of best to worst for the select alloys and graphically represented in Figure 8 for the low-strength alloys (a) and high-strength alloys (b). The 718A, 725 and 690 alloys showed good qualities in testing and will continue for Phase II studies, against the reference $316 \mathrm{~L}$ and $X-750$ alloys. Though the performance of Grade 92 and alloy 310 was less than optimal for certain test criteria, these alloys surpassed $316 \mathrm{~L}$ in IASCC testing under PWR conditions and therefore are considered for Phase II studies. Phase II studies will be focused on neutron irradiation experiments and comprehensive post-irradiation examinations. 
The development of advanced alloys provides the nuclear industry more options in materials selections that can also benefit new plant construction, and continued operation costs of existing plants through improved materials performance.

\section{Exploring the Link Between Strain Localization and Crack Initiation in Irradiated Samples}

IASCC is recognized as a critical concern associated with austenitic steels (e.g., 304L and $316 \mathrm{~L}$ ), which are widely used in the LWR operating environments. Even though several new materials are being considered, including those part of the Advanced Radiation Resistant Materials project of the LWRS program, the 300 series steels are expected to remain in reactor service. As the existing fleet of LWRs ages, the IASCCrelated issues are expected to become a greater concern. Consequently, this issue is being researched by the LWRS program.

IASCC is a complex process involving many contributing factors, including microstructural and microchemical changes induced by irradiation, the corrosive environment and stress loading on the material. Examining the influence of strain localization during deformation of irradiated materials on the initiation of cracking is an important part of understanding the mechanisms of IASCC. However, the examination of materials following failure can be like detective work to analyze the causes of crack initiation when the conditions creating them are no longer present, or worse, eliminated due to further damage created during the failure of the component or sample. To avoid the lengthy reconstruction of the causes of failure in post-tested materials that can also lead to erroneous conclusions, the LWRS Program has begun utilizing a miniature tensile frame (Figure 9) installed in a high resolution dual beam (scanning electron and ion beam microscope) at the Oak Ridge National Laboratory's Low Activation Materials Development and Analysis Laboratory. The instrument is equipped with an array of detectors for imaging, chemical and crystallographic analysis.

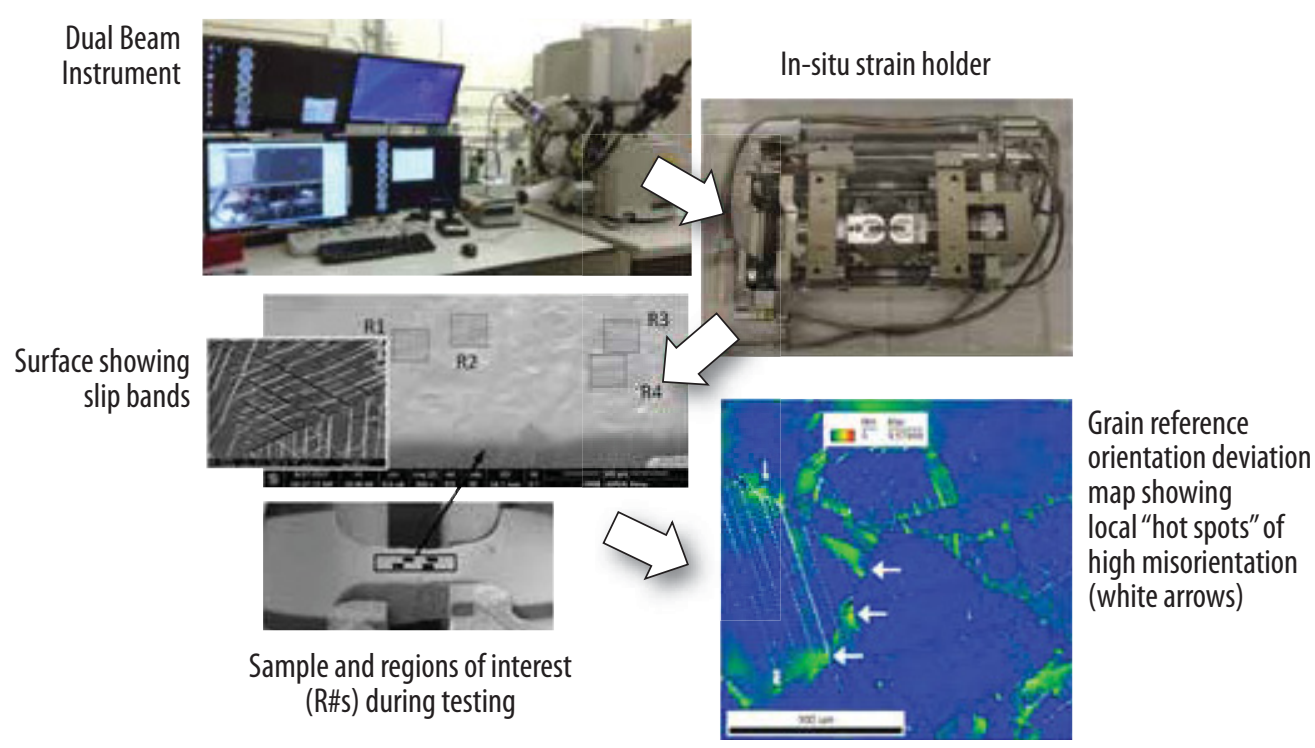

Figure 9. The in-situ strain holder equipped high resolution instrument is used to track changes in irradiated materials undergoing deformation. 
The in-situ sample straining while under examination has already provided a wealth of information on the behavior of materials leading to crack initiation and growth. Systematic research of strain localization in irradiated austenitic steels, performed in the framework of the LWRS Program, revealed the overwhelming complexity of this phenomenon. The in-situ capability has allowed LWRS Program researchers the ability to track, scan, and investigate the selected areas of the sample and analyze straininduced phenomena including grain rotation, changes in the local misorientation, slip line development, and the appearance and evolution of strain-induced twins. During this year, the connection between plastic-strain localization (i.e., dislocation channeling) and crack initiation was confirmed.

These radiation-induced deformation mechanisms continue to be investigated, including the appearance of strain-induced martensitic phases associated with dislocation channels and the formation of specific areas with high local misorientation called deformation "hot spots". Such hot spots may have different corrosion behavior in LWR environments, promoting localized corrosion and increasing susceptibility for IASCC initiation. Understanding the influence of water chemistry at these localized regions and other defects within the material is the objective behind LWRS Program research that has recently begun.

\section{Development of Advanced Weld Repair Technologies for Highly Irradiated Materials}

Weld repair technologies are needed as a critical technology for extending the service life of nuclear power plants beyond 60 years. Control and mitigation of the detrimental

Figure 10. Hot cell operation and advanced welding.

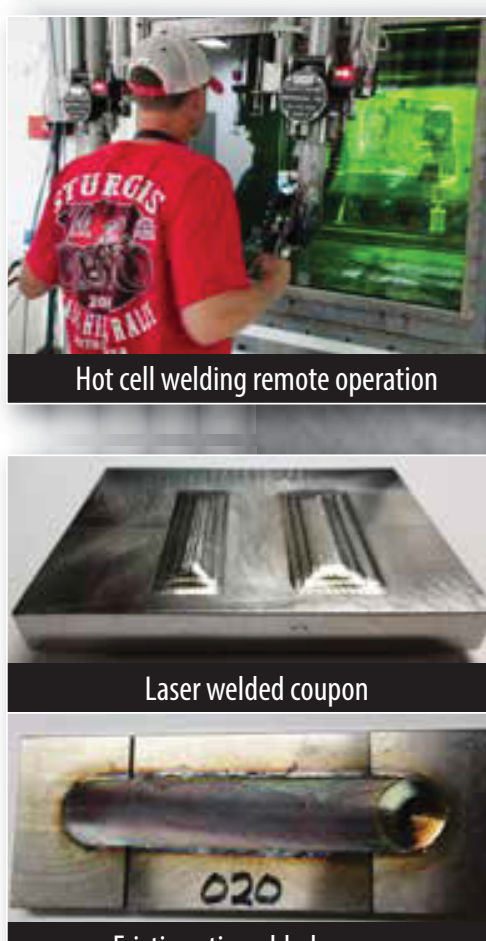

Friction stir welded coupon

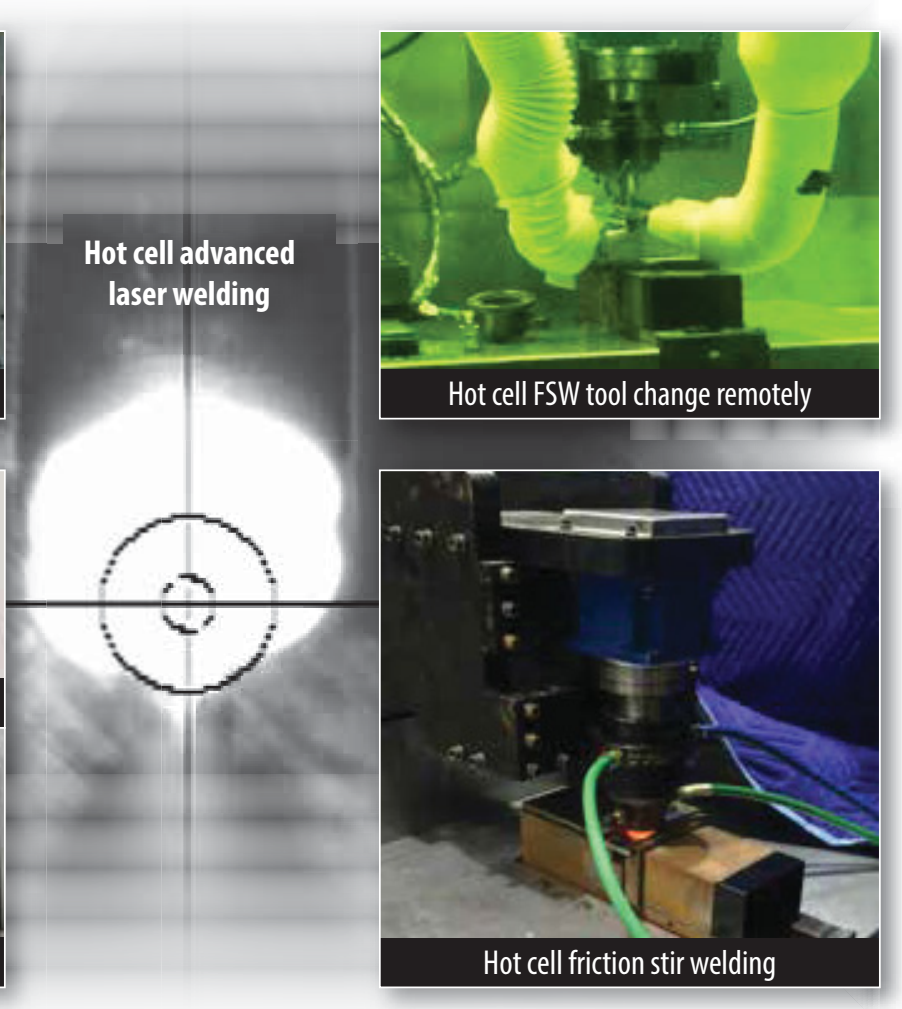


effects of weld residual stresses through management of heat input during welding is required to address the complex challenges associated with welding irradiated components. The LWRS Program, in collaboration with the Electric Power Research Institute, have further developed advanced, state-of-the-art, welding technologies centered on the use of fiber laser welding and friction stir welding techniques.

During 2017, the radiological materials welding cubicle installation was completed at the Radiochemical Engineering Development Center facility at Oak Ridge National Laboratory. The welding cubicle was designed to provide a research facility to identify, test, and validate the performance of the most promising weld technologies directly on irradiated coupons. Through an extensive effort in 2017, all necessary equipment for process control, quality assurance, safety monitoring, transportation of materials, post weld characterization and operation of the cubicle to support research into advanced weld repair has been completed.

During 2017, several further accomplishments were achieved leading up to the start of testing on irradiated materials in November 2017. This included the fabrication of additional test coupons at Oak Ridge National Laboratory with tailored levels of boron, which on irradiation at the High Flux Neutron Reactor, provides materials with concentrations of helium representative of components that have seen over 40 years of service in commercial reactors. Efforts in 2017 also included the development and testing of advanced weld control software to optimize laser welding conditions, and the completion of a study on monitoring the effect of tool wear on the quality of friction stir welding. Laser and friction stir welding tests were performed on nonirradiated materials (see Figure 10 for images) to ensure that welding systems, the hot cell infrastructure, and procedures were ready and complete prior to starting welding operations on irradiated materials.

Demonstration of these advanced techniques for irradiated materials is a key step in validating weld repair as a mitigation strategy for the nuclear industry. Successful deployment of these technologies may provide an alternative to costly core internal replacements. Further, these technologies may also have utility in repair or component replacement applications in other power plant locations that have high susceptibility to stress corrosion cracking due to the reduced weld residual stresses associated with laser and friction stir welding over conventional welding methods.

\section{Improvements in Ultrasonic Imaging of Defects in Thick Heavily Reinforced Concrete}

Portland cement concrete-based structures are typically used in LWR plants to provide the foundation, support, shielding, and containment functions. Degradation of Portland cement concrete to the environment or other defects from fabrication are significant threats to the structural integrity and safe operation of aging LWRs. Moreover, the nondestructive evaluation of LWR reinforced concrete members involves unique complications - such as thick, heavily reinforced structures. The usage of ultrasonic devices to detect faults within concrete specimens has proven to be an effective way to detect damage, see Figure 11. Typically, synthetic aperture focusing technique (SAFT), a Kirchoff-based image processing technique, has been applied to reconstruct ultrasonic signals and increase lateral resolution. SAFT is a heuristic technique that requires the time delays of the system along with the speed 
Figure 11. Acquisition and Reconstruction.

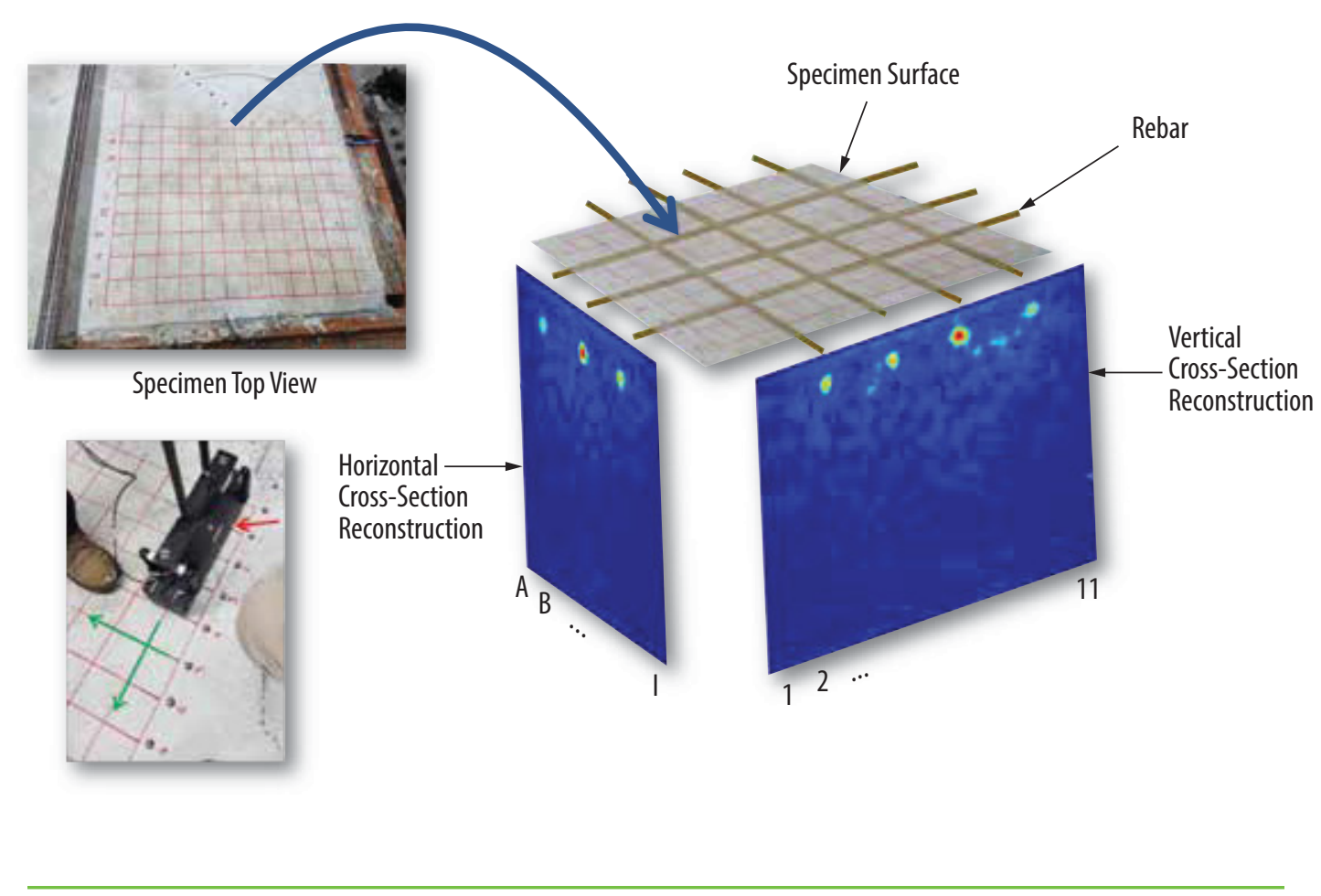

of sound in the material to function properly. However, this reconstruction technique has proven to have several downfalls for thick, heavily reinforced concrete structures. LWRS Program researchers have developed a Model-Based Iterative Reconstructive (MBIR) algorithm that provides quick, high-quality reconstructions. One performance improvement of MBIR is that the system model accepts different acoustic geometries, (e.g., equally spaced transducers), such as the commercial MIRA ultrasonic system; or source non-adjacent to receivers. This is a signification impact because the advanced reconstruction technique can be employed across different nuclear power plant nondestructive evaluation applications.

The LWRS Program has developed a metric that enables the assessment of existing ultrasound reconstruction methods. This ability did not exist and therefore it was impossible to make a direct comparison between MBIR and SAFT techniques and even between MBIR versions. The process (Figure 12) involves the normalization and reconstruction of the signals from the MBIR and SAFT techniques, and evaluating the reconstructed and segmented images against the ground truth component that represents the exact locations of the defects and rebar. Precision and Recall Curves for the reconstructions are generated, based on the matching between the reconstructions and ground truth, providing an illustrative example of the improved performance of MBIR over SAFT. The area under the precision and recall curve provides a score of 0.29 for MBIR against 0.13 for SAFT and correlates with the perceived quality after a visual inspection of the reconstruction.

\section{Modeling Cable Non-Destructive Examination Signals for Improved Cable Health Monitoring}

Cable insulation polymers are among the more susceptible materials to age-related degradation within a nuclear power plant. All plants have developed cable aging 


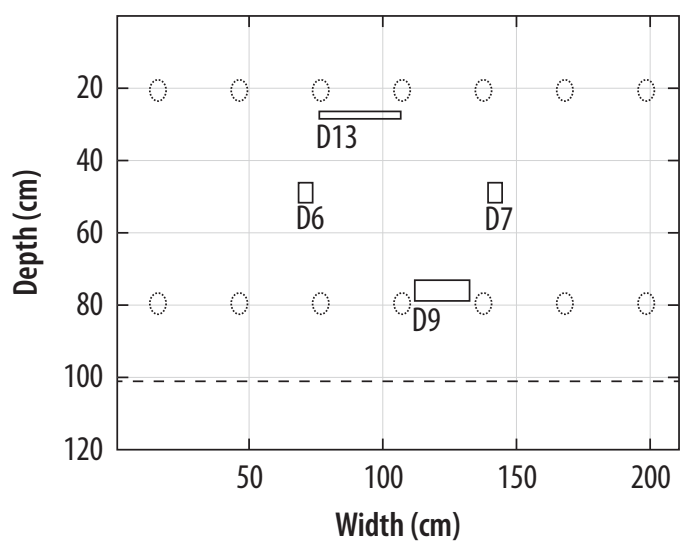

Ground Truth

MBIR 2.5

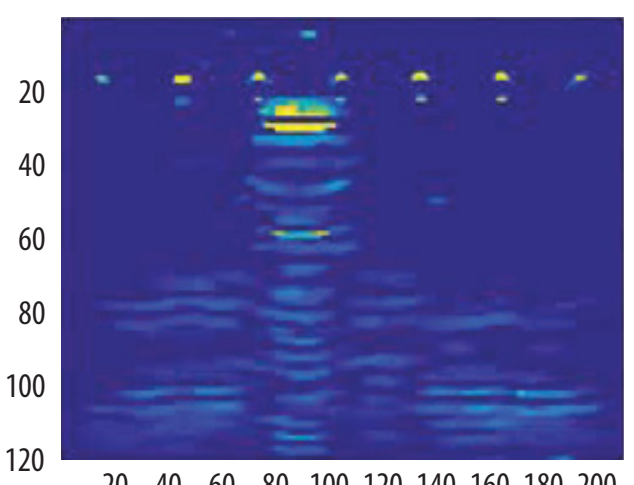

$\begin{array}{llllllllll}20 & 40 & 60 & 80 & 100 & 120 & 140 & 160 & 180 & 200\end{array}$

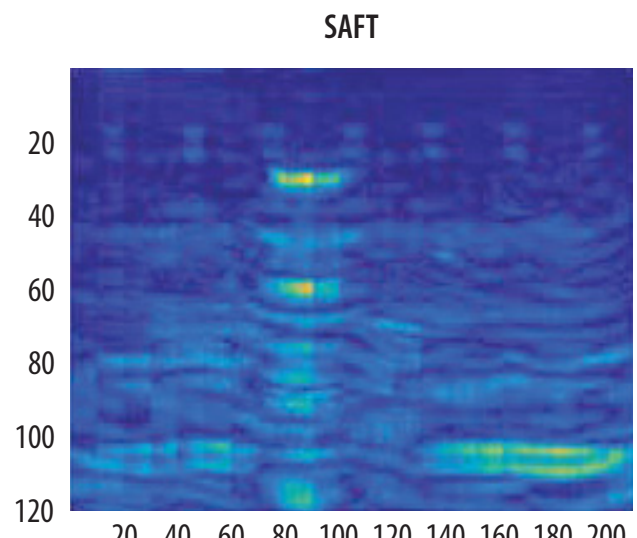

$\begin{array}{llllllllll}20 & 40 & 60 & 80 & 100 & 120 & 140 & 160 & 180 & 200\end{array}$
Figure 12. Reconstruction examples for MBIR (2.5 version) and SAFT techniques of defects in an example thick rebar enforced concrete sample (ground truth) and the corresponding precision and recall curves based on the LWRS Program developed ultrasound reconstruction quality metric.

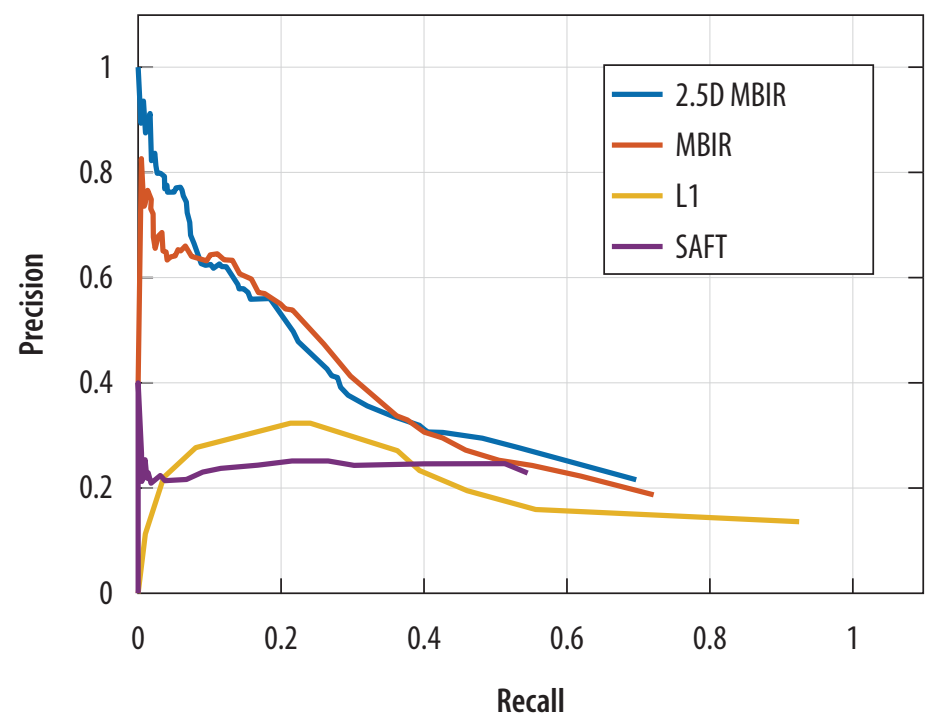

Precision and recall curves for reconstruction 
Figure 13. Block diagram of FDR instrument and cable test arrangement.

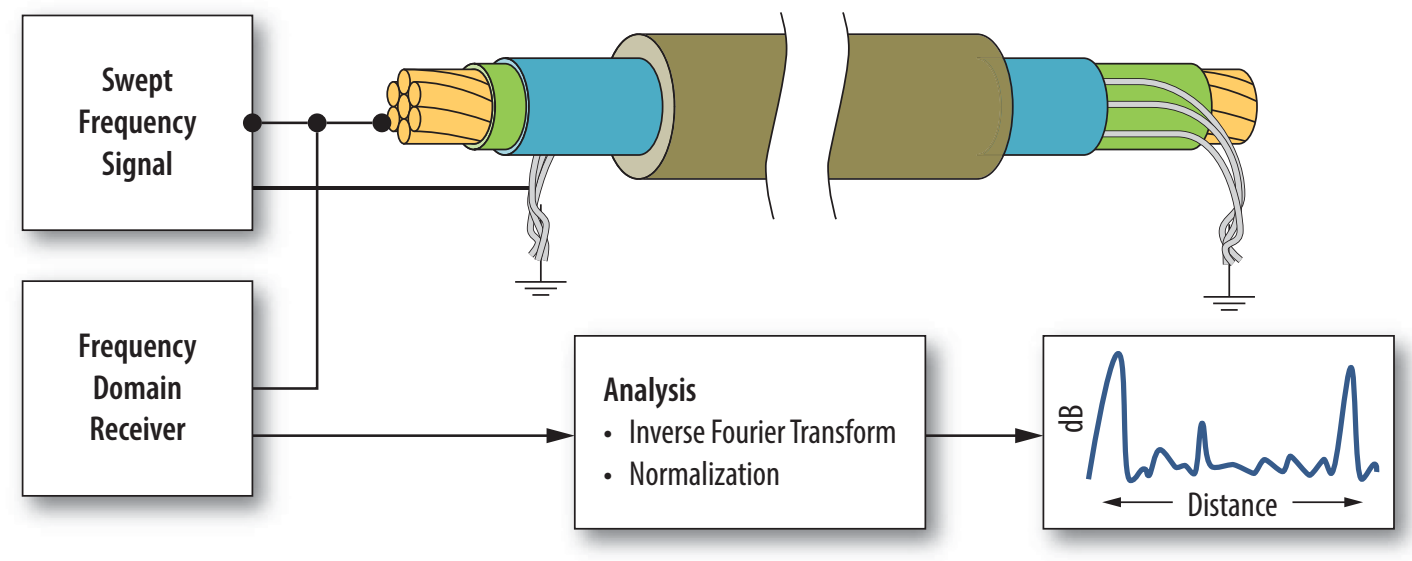

management programs to detect damage before critical component failure in compliance with regulatory guidelines. Cable aging management programs vary in how condition monitoring and nondestructive examinations are conducted as utilities search for the most reliable and cost-effective ways to assess cable system condition. Frequency domain reflectometry (FDR) is emerging as one valuable tool to locate and assess damaged portions of a cable system with minimal cost. In most cases FDR only requires access to one of the cable terminal ends. However, interpretation of FDR responses can be complex and misleading if not coupled with a sound understanding of the measurement physics (Figure 13). Laboratory studies to evaluate the use of FDR for inspection of aged cables can be expensive and data interpretation may be confounded by multiple factors which influence results. Therefore, a model-based approach is desired to isolate and assess the influence of a number of parameters affecting the FDR response.

In 2017 a physics-based system model was developed to represent the cable and measurement system. Cable and measurement parameters such as change in dielectric coefficient (typical of thermal and radiation damage), damaged section length, damage profile, cable type (coaxial, parallel or twisted pair, shielded, etc.), termination impedance, and FDR band-width were changed to assess the theoretical influence on the FDR signal response. Some of these theoretical system parameter changes were also implemented in test samples to verify the model. The benchmark test cases agreed with the model thereby validating it for the more complete set of parametric assessments. Evaluation of the model against experimental conditions was conducted for different cable damage section lengths, locations of defects, numbers of defects and gradients of damage in the cable. This work is captured in the report titled, Physics-Based Modeling of Cable Insulation Conditions for Frequency Domain Reflectometry (FDR), PNNL-26493 (Figure 14). 

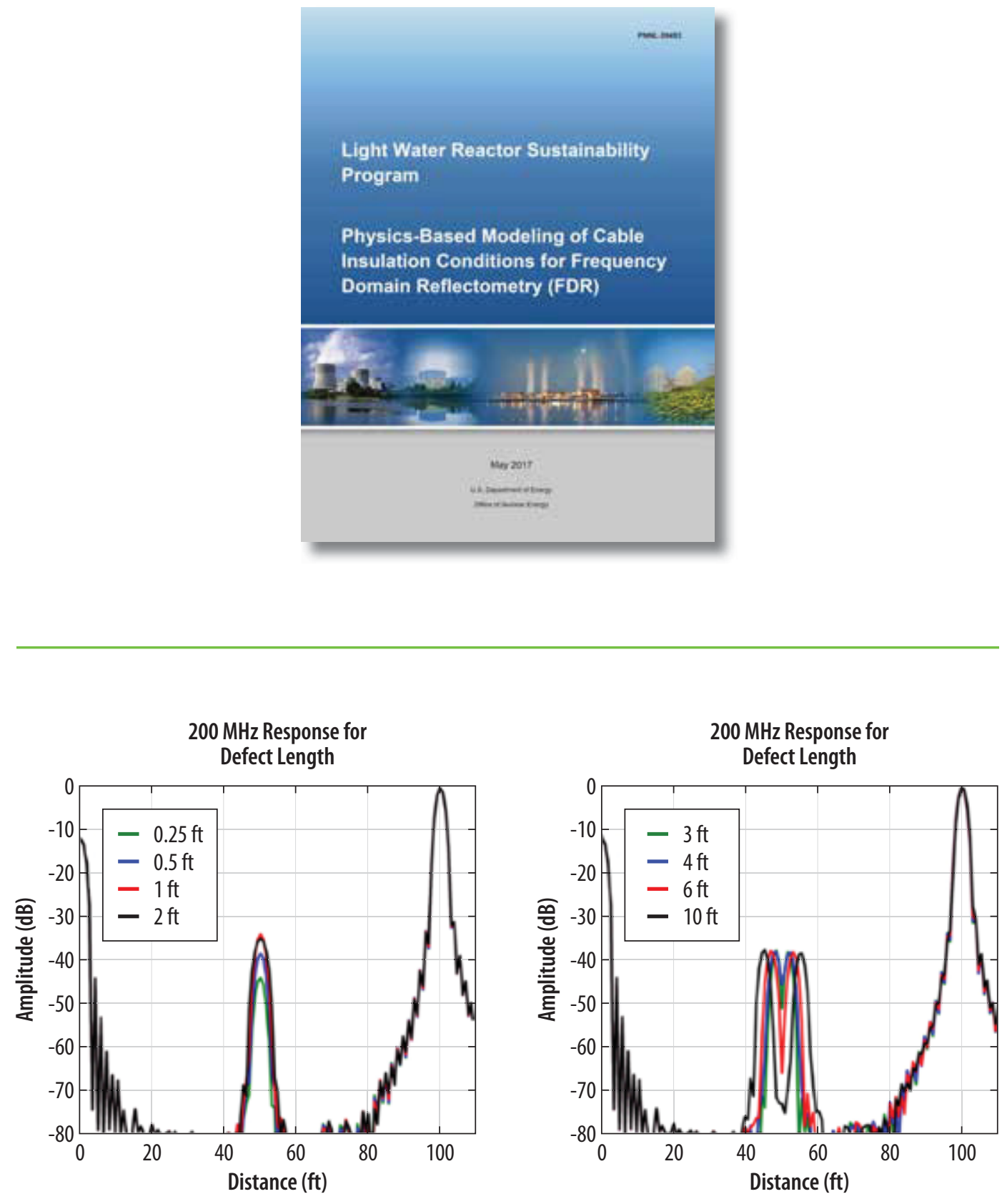

Figure 14. Physics-Based Modeling of Cable Insulation Conditions for Frequency Domain Reflectometry (FDR).

Figure 15. Differences in FDR signal responses in simulations for increases in insulation dielectric constant for (left) relatively short defect lengths ( $<1$ wavelength at maximum frequency, with defect lengths listed in the figure key) and (right) relatively long defect lengths in shielded triad cable.

This modeling effort provided significant insight for a small set of cables examined and showed the complex signal response to different defect types and conditions (Figure 15). The research performed on modeling cable monitoring signal response will improve the accuracy of cable aging management programs for varying paired conductors and other more complex cable designs. The work may also be extended to assessing other frequency domain tests such as dielectric spectroscopy and joint time frequency domain reflectometry. 


\section{Advanced Instrumentation, Information, and Control Systems Technologies}

(n)

fforts in the Advanced Instrumentation, Information, and Control (II\&C) Systems Technologies Pathway address safe and efficient modernization of the current instrumentation and control technologies used in nuclear power plants. This is done through development and testing of new instrumentation and control technologies and advanced condition monitoring technologies for more automated and reliable plant operation. The research and development products are used to design and deploy new technologies and systems in existing nuclear power plants that provide an enhanced understanding of plant operating conditions and available margins and improved response strategies and capabilities for operational events. The goals are to enhance nuclear safety, increase productivity, and improve overall plant performance. Pathway researchers work with nuclear utilities to develop instrumentation and control technologies and solutions to support the safe and reliable long-term operation of current nuclear power plants.

\section{Research Highlights}

Select research and development highlights are provide here. Detailed reports covering the accomplishments can be found on the LWRS Program website (https:// Iwrs.inl.gov).

\section{Introduction}

Today's operating LWR fleet relies on an aging instrumentation and control infrastructure of 1960's-vintage analog technologies. Nuclear utilities are spending considerable efforts and resources to maintain these declining technologies that have largely been abandoned by other power generation sectors. This approach extends current conditions at a time when the operating fleet has an urgent need to restructure its operating cost basis to remain competitive in the U.S. electricity market.

The Advanced II\&C Systems Technologies Pathway is developing advanced digital applications that address both of these needs - to modernize the instrumentation and control infrastructure in a manner that lowers operating cost while improving plant performance.

\section{Control Room Modernization}

Control room modernization represents a critical need for the operating LWR fleet in updating operator controls with state-of-the-art digital technologies now commonplace in other safety-critical industries. The challenge is defining a migration path for the introduction of advanced digital technologies that is affordable and not disruptive to the ongoing operations of the nuclear power plants. For operating plants, the human factors issues are even more challenging for a hybrid control room (mixture of analog and digital technologies) than for a new, fully-digital plant. This lack of a migration path for hybrid control rooms has been a significant barrier in upgrading the control rooms leaving them with maintaining declining analog technologies and forgoing the efficiency and operator performance improvement benefits that digital technologies afford. 

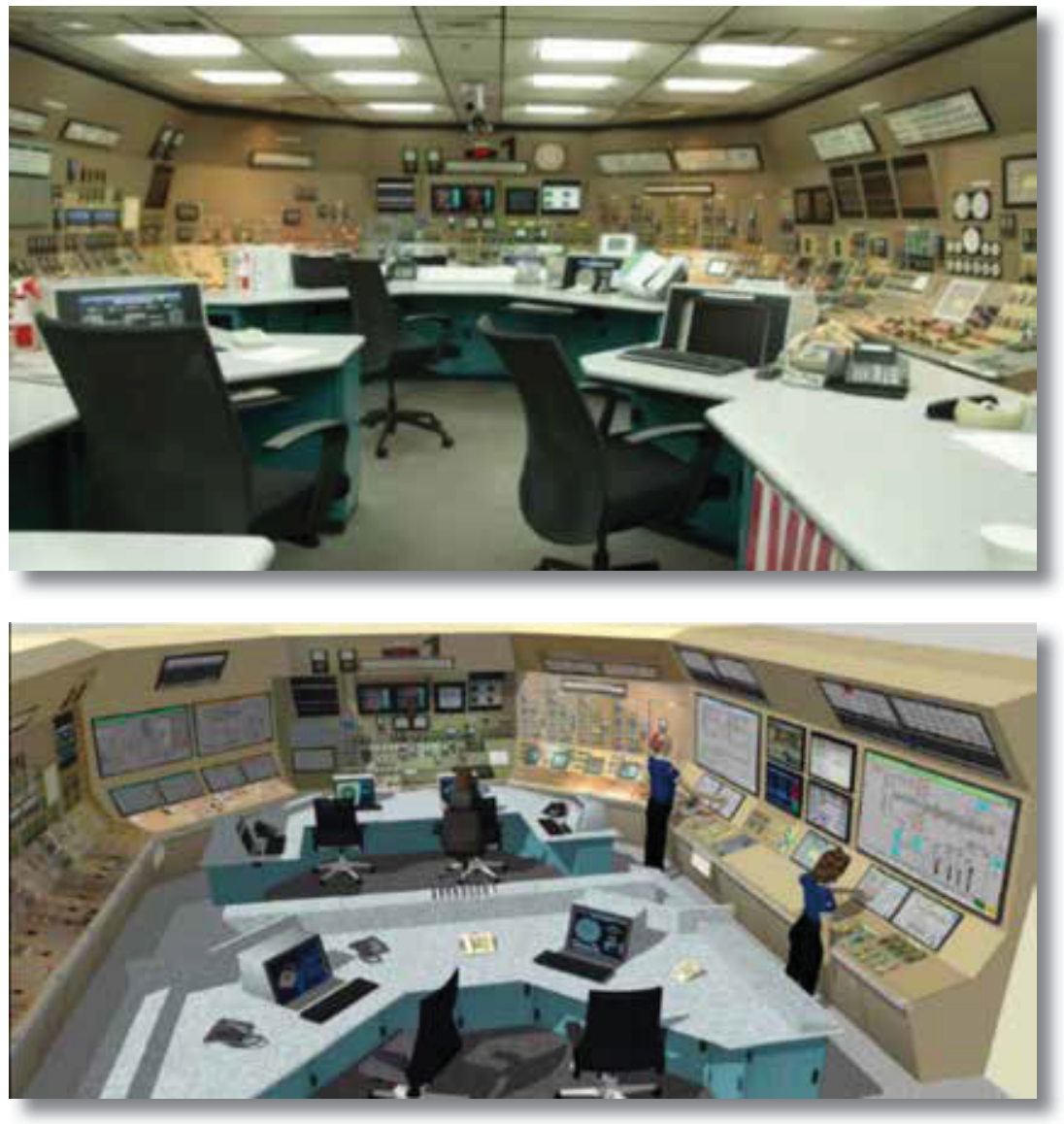

Figure 16. Advanced Hybrid Control Room for Palo Verde Nuclear Generating Station.

The LWRS Program is collaborating with Arizona Public Service, operator of the nation's largest nuclear power plant, the Palo Verde Nuclear Generating Station (i.e., Palo Verde), to define this migration path. During 2017, LWRS Program research staff integrated new technologies into the Palo Verde training simulator using the turbine control system as the first of many system upgrades. Figure 16 depicts the design of a large task overview and control displays that includes the replacement of a number of discrete analog control and indication devices with a digital system. These displays employ a number of human factors improvements such as dynamic groupings of plant information tailored to specific tasks, information-rich graphics that support improved situational awareness, the potential for use of computer-based procedures, and use of advanced operator advisory systems.

Studies were conducted on the simulator mock-up with licensed operators from Palo Verde, using performance measuring methods and tools that provide objective evidence of performance improvement and the superiority of one particular control display over another. This research has confirmed that the advanced digital replacement technologies proposed in future designs afford improvements over current technologies.

Similar research activities were conducted for the modernization of local control rooms in specialized areas commonly found in nuclear power plants. LWRS Program researchers worked with a current design to transform a prototypical Liquid Radiological Waste 
Figure 17. Transformation of the Palo Verde Liquid Radiological Waste System control room.
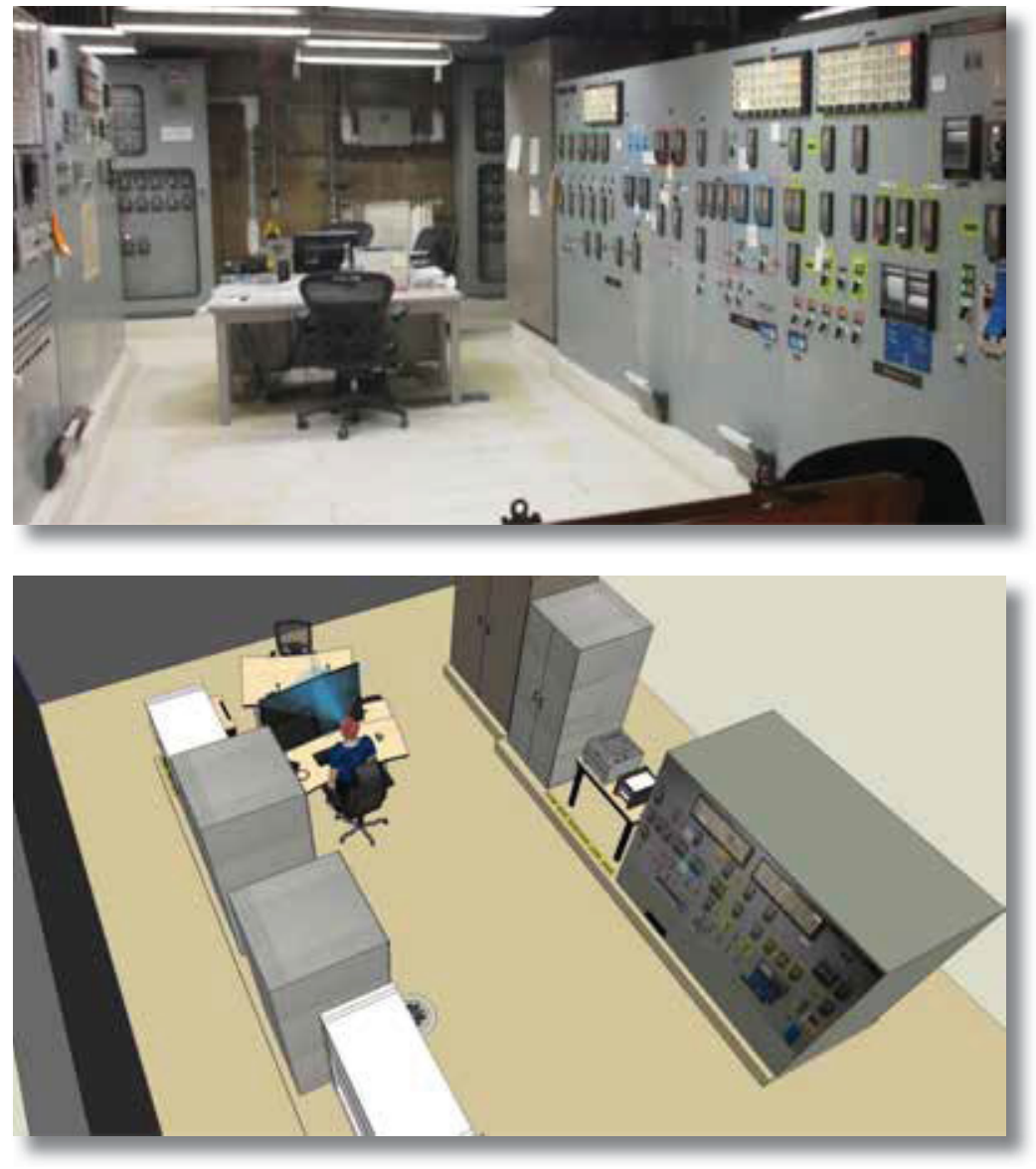

System control room from a group of upright analog control panels to a compact digital operator control station, as depicted in Figure 17.

Key research topics included the human factors considerations for the operator console, alarm presentation, and use of information-rich graphics to convey appropriate situational awareness.

The LWRS Program is also conducting research in addressing control room modernization for a large nuclear operating fleet, looking for efficiencies in standardization. Exelon Nuclear is serving as a research collaborator involving planned upgrades for their Braidwood and Byron nuclear stations. In this case, a single model is serving as a prototype for both stations, enabling human factors studies that will serve as a technical basis for both stations. Figure 18 depicts how human factors technology is used to ensure ergonomic factors meet standards in the area of operator vision and reach.

The LWRS Program is developing valuable control room modernization technologies for the LWR fleet while defining a viable migration path for their implementation through these collaborations with first-mover nuclear utilities. In turn, these utilities are gaining direct assistance in employing these technologies in a manner that complies with sound human factors principles. 


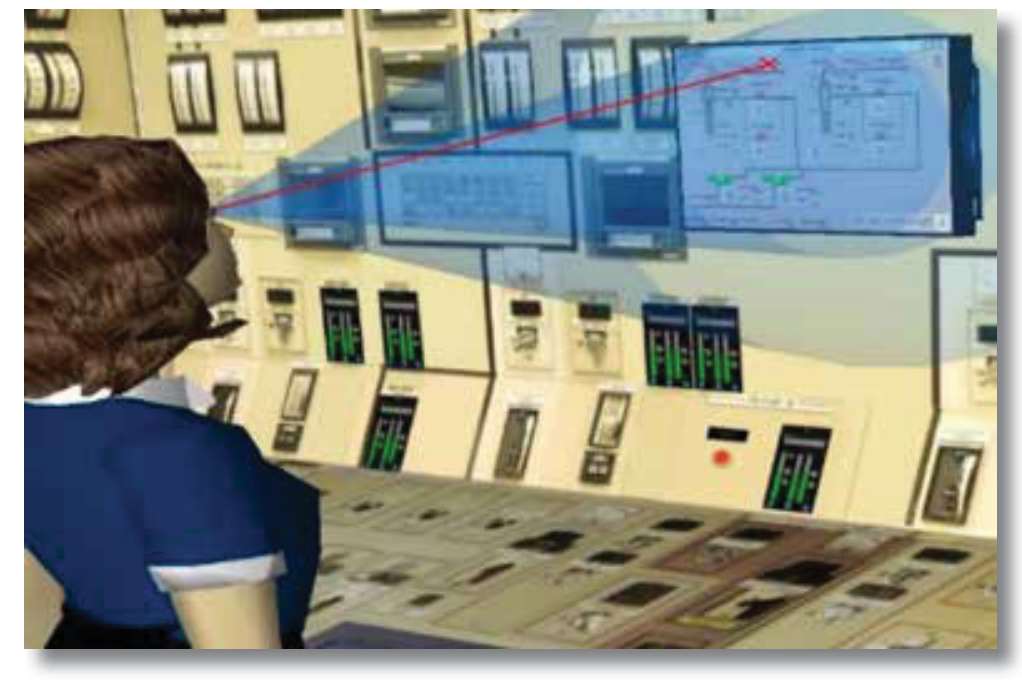

Figure 18. Human factors verification for operator vision and reach.

\section{Control Room Modernization Business Case}

In spite of a significant number of digital systems now having been implemented in operating nuclear power plants, there have been few large scale changes to the configuration of discrete instrumentation and control systems or layout or function of their control rooms. Nuclear utilities have understandably been reluctant to undertake significant control room upgrades or modernization projects in consideration of cost, regulatory risk, and impact on the large investment in procedures, training programs, and other support functions that may accompany large upgrades.

The lack of a business case is often cited by utilities as a barrier to pursuing integration and control room improvements in conjunction with digital instrumentation and control upgrades. It has been difficult to identify actual cost reductions that can be credited to budgets and thereby truly reduce operating and management or capital costs. Technology enhancements, while enhancing work methods and making work more efficient, often fail to eliminate workload in a manner that results in overall staffing and material cost reductions. Demonstrating cost reductions or impacts on non-cost performance objectives is critical in order for the business case to justify investment by nuclear operators.

To address this need, a study was undertaken to quantify the benefits of control room modernization as a reference for the industry to structure their own specific business case for modernization. The study differentiated the amount of benefits that comes from either partial or full digital modernization. The partial case is known as the hybrid control room, in which there is a mixture of new digital and legacy analog instrumentation and control technologies. The fully integrated control room, also known as compact control room digital modernization, represents the case where all legacy analog instrumentation and control systems, as well as the control room human-system interface technology, has been upgraded to digital.

A business case methodology was employed that is designed to analyze the cost savings of implementing new technologies in the context of a typical nuclear plant organization. The methodology is based on identifying opportunities to reduce costs that are enabled by new digital instrumentation and control and other control room technologies. 


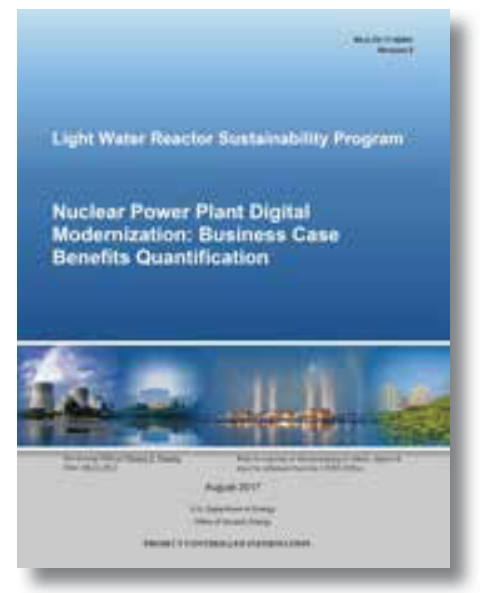

Figure 19. Nuclear Power Plant Digital Modernization: Business Case Benefits Quantification.
Nine categories of cost reduction opportunities were investigated to determine how future operating costs could be reduced as a result of the approaches to digital modernization considered, and these are documented in a report entitled "Nuclear Power Plant Modernization: Business Case Quantification" (Figure 19). Arizona Public Service's Palo Verde Generating Station provided plant data to conduct the study. However, it should be noted that this study does not necessarily reflect their plans or future intentions with respect to digital modernization.

For the hybrid control room business case, the study resulted in a projection of over $\$ 14 \mathrm{M}$ of annual savings. Major drivers of the savings were improved human factors in the control room leading to greater operational efficiency, the reduction in operator error, and reduction in plant events leading to generation loss.

For the digital control room business case, the study projected over $\$ 20 \mathrm{M}$ of annual savings. Major drivers of the savings were the reduction in operations staffing due to significant improvements in human systems interface and automation, and the reduction in staff and materials to support instrumentation and control maintenance and testing due to a highly integrated design that replaces most conventional relay and analog components with digital controllers and digital data communication that eliminate single point vulnerabilities and employ continuous self-testing.

\section{Advanced Digital Technologies}

During 2017, LWRS Program researchers worked with Xcel Energy Inc. to develop and test the potential and feasibility of several automation technologies reflecting current work processes of nuclear power plants. These technologies have the potential to lower the cost of maintenance as well as to enable performing work with higher quality and accuracy than the manual methods used today.

The research approach involved building customized and application-oriented automated work process prototypes and then evaluating the new prototypes through dedicated user studies. This approach directed the evaluation towards the targeted applications, and enabled the researchers to acquire application specific findings, that would not otherwise be obtained using generic products. Three dedicated prototypes were developed and tested for several applications.

The ultra-high frequency radio frequency identification prototype was developed to overcome challenges related to materials, tools, and equipment including overcoming discrepancies in the accountability of foreign materials exclusions zones, that often impacts the plant critical path, and is therefore very expensive. Examples of radio frequency identifiers are shown in Figure 20. The prototype also eliminated the need for re-work and the safety consequences of using improper use of materials, tools, and equipment in maintenance work packages, because it enabled automatic tool fitness verification. Taking inventory of outage containers is required prior to the beginning of a plant outage. However, this process (one of several such pre-outage activities) is typically manual, which makes it time consuming and costly. Using the prototype, it was found that creating inventory lists and searching for specific items in these containers can be performed in a matter of seconds per container using the installed ultra-high frequency radio frequency identifier, thereby reducing the time of the whole process to a few hours of one craft person instead of weeks of multiple craft personnel. Other benefits of the use of ultra-high frequency radio frequency identification includes tagging 

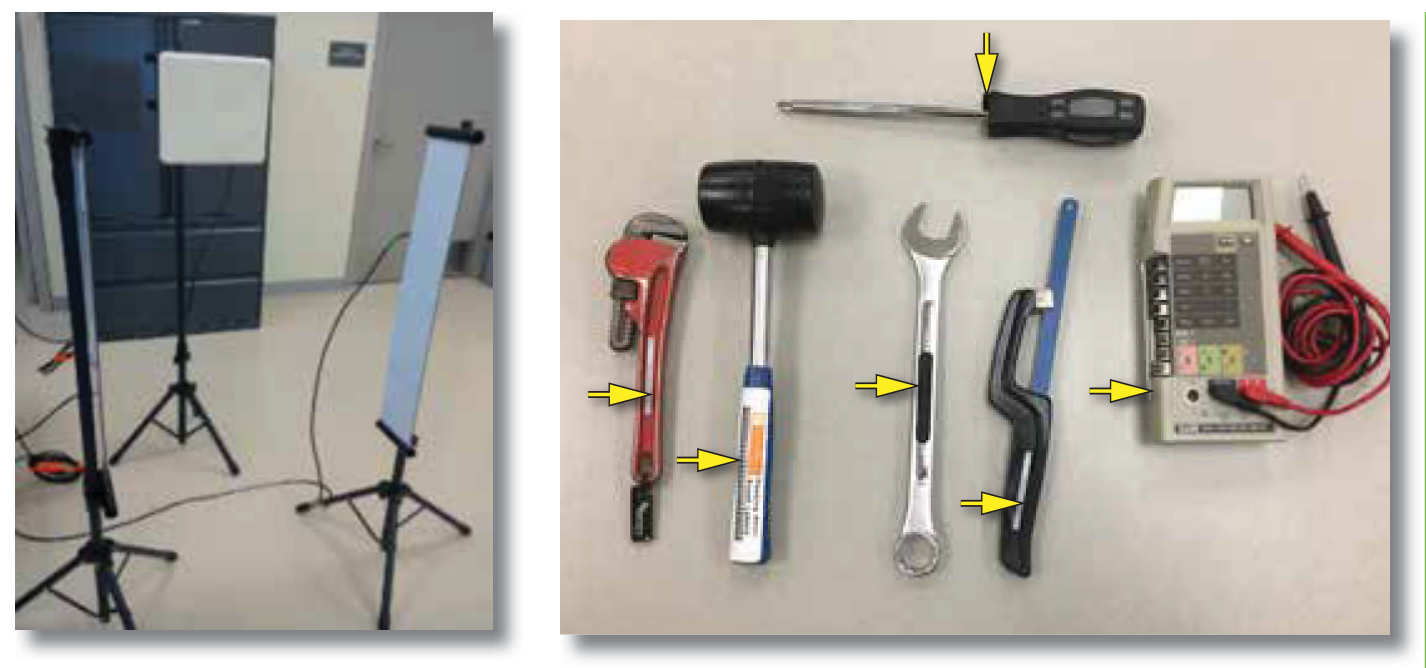

Figure 20. Radio frequency identification of tools for foreign material exclusion.

contaminated materials, tools, and equipment and installing antennae at contamination zones gates to prevent the removal of contaminated parts. This adds another layer of safety defense to the current approach of painting contaminated parts. The same approach can be used to prevent removal of certain materials, tools, and equipment from the plant, and to keep track of the calibration status of tools and equipment.

Automatic location identification using Bluetooth low energy beacons was also developed and tested. The prototype developed was designed to electronically alert the workers to safety hazards in their area. This is useful since many plants are moving towards deploying electronic work packages on mobile devices, which could result in the distraction of the worker from their physical environment. The Bluetooth low energy beacon prototype was also developed and tested to resolve another challenge associated with mobile devices that is to switch off the radio signals transmitters as workers enter radio exclusion zones in nuclear power plants. The means to automate this process was developed and tested, thereby adding another layer of safety and regulatory defense, especially as plants rely more on mobile devices

Though video monitoring and recording has advanced for multiple applications, the nuclear power industry has been hesitant to adopt this capability. A prototype was developed to target integrating video monitoring and recording in the work process. The prototype was customized towards enabling peer reviews, therefore often eliminating the need of two craft team members. The prototype was also customized towards remote supervision to enable one supervisor in tracking the progress of multiple work activities at the same time. Both of these applications result in significant labor time savings and efficiency improvements. The prototype was also equipped with recording capability to facilitate video creation for training, pre-job briefings, and quality reviews. The design of the prototype included human factors engineering to enable it to be learned in a matter of minutes.

\section{On-Line Monitoring of Concrete}

The acceptable health and condition of concrete is critical to the structural integrity of a nuclear power plant and is fundamental to its safety basis. Yet, no technologies can accurately examine the interior portions of large concrete structures to assess their 
structural health or detect and characterize early degradation mechanisms before they become apparent in surface cracks and other forms of resultant damage.

To address this need, the LWRS Program is conducting research with other partners to develop a structural health monitoring framework for concrete structures in nuclear power plants. During 2017 research focused on the development of capabilities to enable detection and diagnosis of damage in concrete structures due to alkali-silica reaction (ASR). ASR is one form of degradation of concrete. The outcome of this research will be used to study other mechanisms of degradation in concrete and the means to detect, characterize and diagnose them. This involved investigating the applicability of a dynamics-based health monitoring methodology (i.e., vibro-acoustic modulation) for detection and localization of ASR-induced damage. The vibro-acoustic modulationbased health monitoring method interprets signatures of nonlinear structural behavior in the frequency-domain response of a dynamically excited structural component as indicators of damage. It can potentially provide a low-cost, reliable, easy-to-implement protocol for health monitoring of nuclear power plant concrete structures.

The research during 2017 used laboratory experiments at Vanderbilt University to investigate the vibro-acoustic modulation-based structural health monitoring methodology. A concrete slab (of size $24 \times 24 \times 6$ in.) cast in December 2015 began showing ASR-related damage during the fall 2016. The vibro-acoustic modulation test included instrumenting the surface of the slab with accelerometers and applying two simultaneous excitations to the slab, one with low-frequency (pumping) and one with high-frequency (probing). The power spectral density analysis of the acoustic signals recorded by the accelerometers indicated the presence of ASR-induced cracks in the specimen, and satisfied the detection objective. In addition, variance of raw acoustical signal was generated to expedite the analysis in the frequency domain. In order to localize the ASR-related damage, the relative magnitudes of side-bands at various

Figure 21. The "damage map" for ASR-related damage in a concrete casting.
Sum of Sidebands

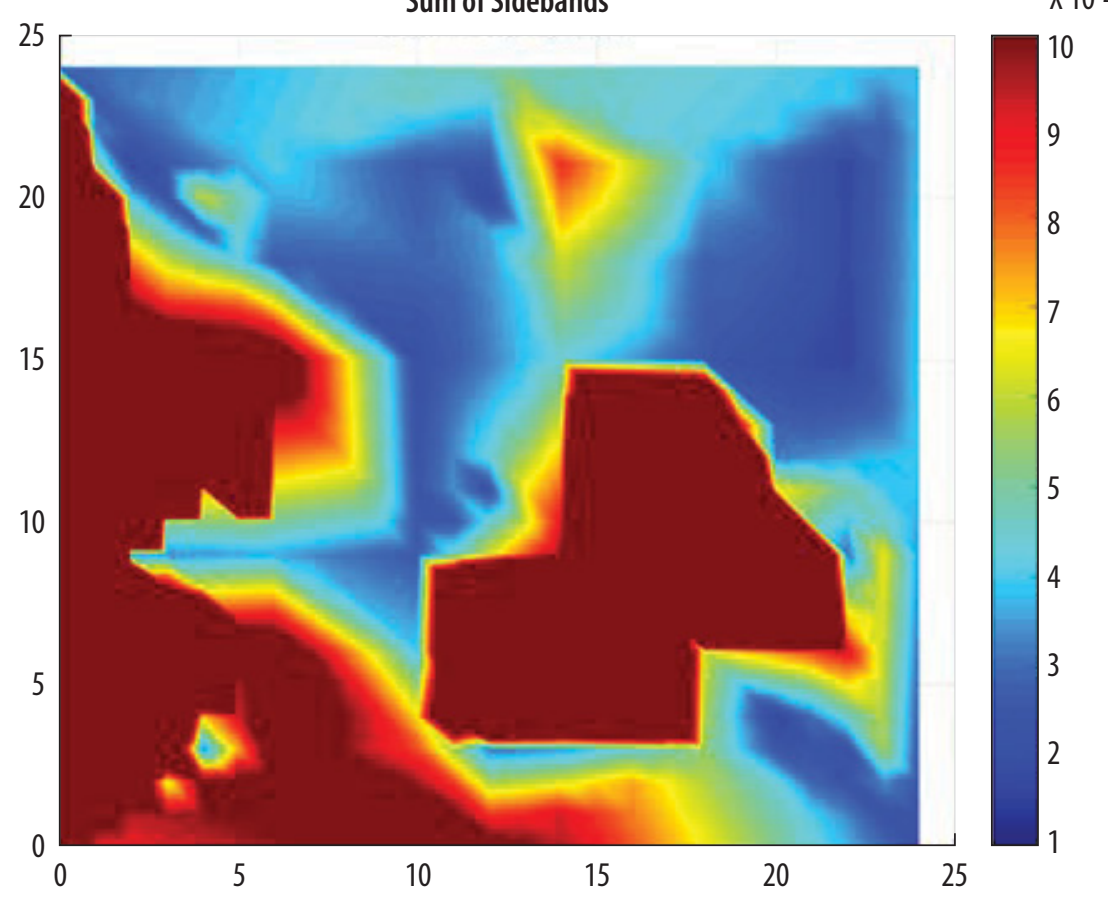


location were used to plot a "damage-map" (Figure 21) that indicates the extent of damage at various locations. Analysis of time-evolution of such damage maps, for a given pump-probe-sensor configuration, provides valuable information about the health of the concrete component in question. Multiple sensor layouts and the resulting observations at different frequencies, amplitudes and locations of the pumping and probing excitations were studied. Future research and development efforts will include the continued development of the sensor and signal processing techniques developed to date with a goal of improving the specificity of diagnostics and accuracy of results in characterizing concrete damage in concrete samples. The long-term goal of this research is to develop diagnostically accurate techniques that can be used to monitor the health and performance of concrete structures in their in-service environments.

\section{Structural Health Monitoring for Nuclear Power Plant Secondary Piping}

The piping system is one of the most extensive and vital systems in nuclear power plants, with inspections performed on a regular basis. The technical basis for the inspection period are based on predictive analysis or operating experience. Due to the significant numbers, length, age, and locations of piping systems, localizing piping locations for timely inspection is a challenge. The relatively recent development of ultrasonic guided waves technology offers new possibilities for the reliable and economic inspection of large portions of piping systems.

The LWRS Program has begun to evaluate technologies that could be used to perform online monitoring of piping and other secondary system structural components in commercial nuclear power plants to monitor their structural performance and that could also provide early indications of both aging and degradation. These online monitoring systems have the potential to identify potential wall thinning in piping to trigger a more detailed inspection using enhanced measurements. It is envisioned that while a plant is online producing power, an integrated monitoring system can perform data processing, data fusion, and decision making about the condition of piping to provide end users with a characterization of the piping system, specifically the evaluation of wall thickness and the remaining useful life of pipes. The integrated online monitoring system will interface with the data acquisition structure by accessing reconciled data files. A conceptual representation of the system's output is shown in Figure 22.

Figure 22 depicts a conceptual representation of the online monitoring system's output. The wall thickness is color coded with green representing the safe thickness, yellow-borderline thickness, and red representing the wall thickness close to margin or threshold, that requires attention.

In 2017, research focused on developing two approaches to suppress coherent noise in guided wave systems: (1) advanced signal processing and pattern recognition based on independent component analysis, and (2) a hardware-based technique using piezoelectric paint, that can be used to facilitate propagation of mechanical stress waves through piping. It was demonstrated, using simulated guided wave data, that independent component analysis is capable of separating different coherent noise components and segregating them from useful signals. The piezoelectric paint approach also appears to be a viable alternative to signal processing methods. Future work will employ data from plant monitoring locations to enable testing of signal processing algorithms and to advance the piezo-electric paint technology for in-situ monitoring of piping to provide better structural health monitoring capabilities for nuclear power plant systems. 
Figure 22. Piping system representation of degrees of degradation.

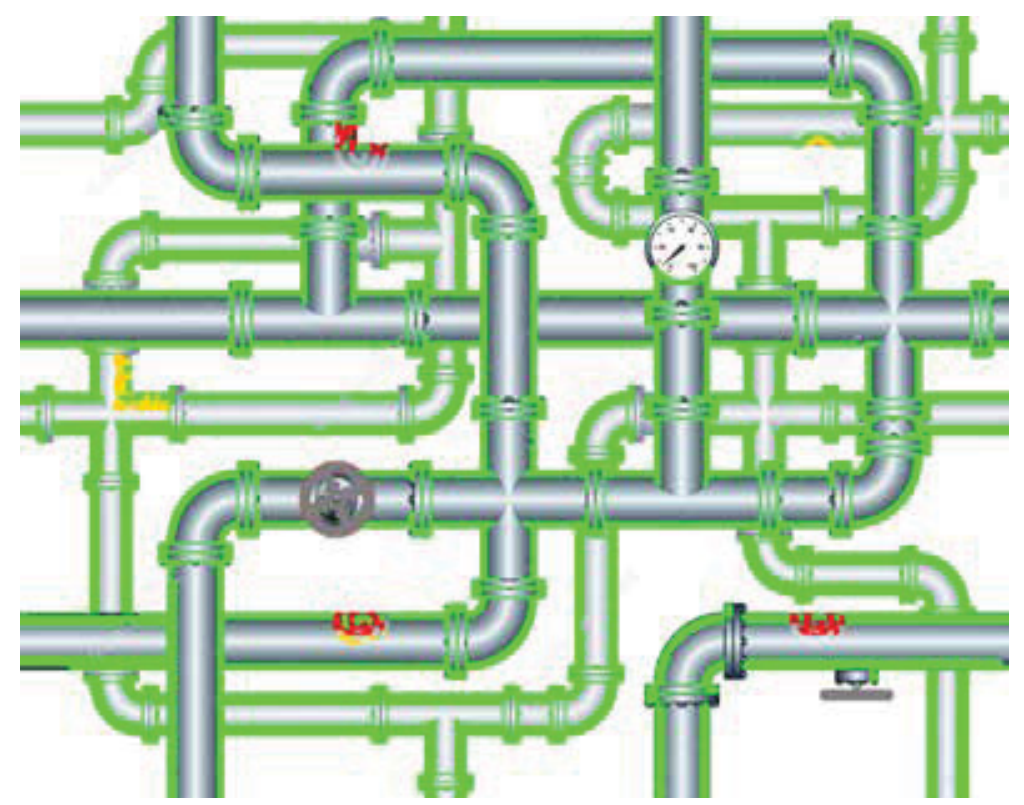

\section{Data Analytics for Nuclear Power Plant Cost Reduction}

During nuclear power plant refueling and maintenance outages, plant configuration and associated risks, as well as requirements for systems, are monitored and verified by a number of experts. In trying to identify plant impacts of planned activities, major evolutions, and contingent activities, crews are guided by procedures, checklists, knowledge, and experience. They aim to ensure potential risks are effectively managed by building outage schedules that place work into phases, called work windows, in which they ensure that plant conditions comply with Technical Specifications.

Non-compliance with Technical Specifications effectively constitutes a license violation that is reportable to the U.S. Nuclear Regulatory Commission, and can also lead to equipment damage or accidents. Relying on procedures, checklists and experience to manage risks has been found to be occasionally inadequate. Better access to key safety and operational performance parameters could contribute significantly to situation awareness and the outage crew's ability to understand the risks associated with changing conditions during an outage.

Control room and outage control center staff must be continually informed about the actual state of the operational and maintained systems. Frequent outage control center meetings certainly help to promote the information flow, but an effective system configuration and risk monitoring system will be a useful tool to support the decisionmaking process. There is an opportunity to leverage several technologies to assist control room and outage control center personnel in monitoring and verifying that current requirements will allow the planned work. Making outage key performance parameters and requirements and the relationships among them visible in real-time would enable all personnel to anticipate and prepare for the configuration changes and requirements during plant evolutions. It would support frequent re-evaluation of the existing outage configuration and help to estimate the effects of planned interventions 


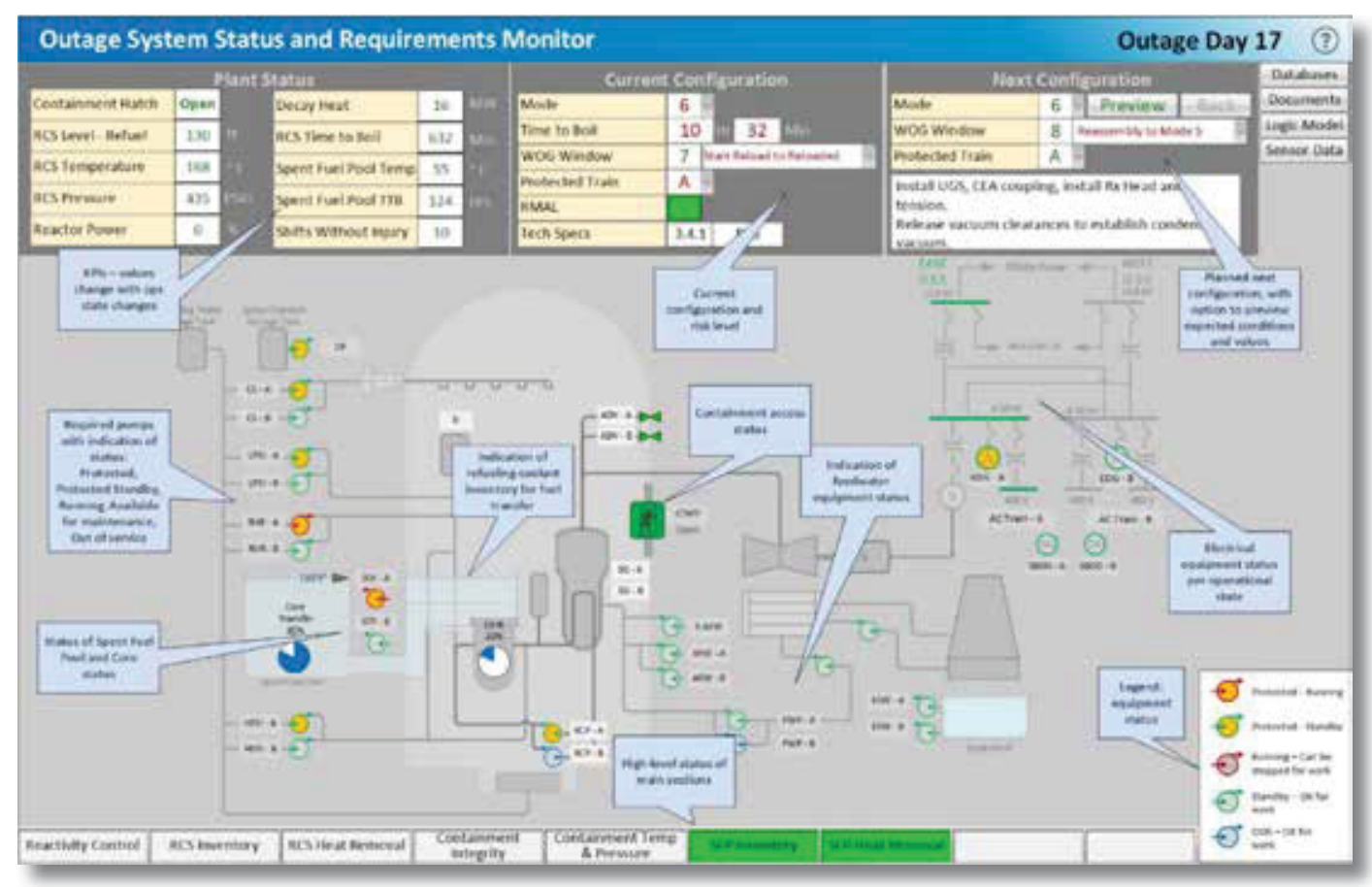

Figure 23. Outage System Status and Requirements Monitor Interface Concept.

and corrective actions. In addition, easy access to system configuration information would support preparation of a daily risk report, that in turn would support the decisionmaking process and handling of unexpected deviations from the outage plan.

In 2017, research was conducted in data analytics to integrate data from different sources of information used to manage outages to improve nuclear power plant outage management and to reduce outage risk. This research is being used to develop a software application called an Outage System Status and Requirements Monitor. The Outage System Status and Requirements Monitor is an information collection, processing and visualization tool, being developed through data analytics research to assist staff in maintaining awareness of ever-changing conditions and requirements, for example, the status of critical plant equipment, including reactor protection system, equipment cooling systems, residual heat removal, emergency diesel generators, etc. In addition, it can be used to accurately track the status of plant equipment required during specific outage work windows. The application will not replace any existing system at the plant, but will interface with a number of existing systems, including the plant process computer and various plant information systems and databases. Text mining of scheduled procedures and work orders will attempt to predict future plant configuration states and prevent conflicts between procedures and prevent non-compliance issues with technical specifications or shutdown safety plans. Figure 23 shows an example of a conceptual user interface for data integration and display that is currently being evaluated.

There are several areas where improved data analytics techniques may be used to improve outage management. Previous LWRS Program sponsored research in outage technologies has resulted in new dashboard concepts that use historical outage data to help evaluate current outage performance and identify groups that may be falling behind. The current research is focused on integrating data from multiple sources to ensure work activities do not place the plant in an undesired configuration. 


\section{Risk-Informed Safety Margin Characterization}

The purpose of research and development work performed under the Risk-Informed Safety Margins Characterization (RISMC) Pathway is to support plant decisions for risk-informed margins management with the aim to improve economics and reliability, and to sustain safety of current nuclear power plants over periods of extended plant operations. The goals of the RISMC Pathway are twofold: (1) develop and demonstrate a risk-assessment method that is coupled to safety margin quantification that can be used by nuclear power plants as a part of risk-informed margin management strategies; and (2) create an advanced RISMC Toolkit to enable more accurate representation of nuclear power plant safety margins and their relationship with operations and economics.

\section{Research Highlights}

Select research and development highlights are provide here. Detailed reports covering the accomplishments can be found on the LWRS Program website (https:// Iwrs.inl.gov).

\section{The Risk Analysis and Virtual ENvironment (RAVEN) Toolkit}

In 2017, the RISMC Pathway released the Risk Analysis and Virtual ENvironment (RAVEN) open-source software on the GitHub website (https://github.com/idaholab/ raven). The software is available for nuclear plant safety collaboration and for other researchers to expand the feature set. RAVEN is a unique and powerful tool for dynamic risk analysis using simulation, offering capabilities not currently available in other software. RAVEN offers a fully integrated working environment that provides a probabilistic framework engineers and scientists need to tackle challenging problems in an efficient fashion. RAVEN is a flexible probabilistic analysis framework allowing users to perform a variety of dynamic analysis, data mining and model optimization tasks. These operations are performed based on the response of complex physical models through advanced sampling generation to achieve a high degree of realism and accuracy previously unattainable.

RAVEN has been designed to interface with and control other nuclear codes and RISMC Toolkit software such as the simulation code for characterizing the behavior of nuclear power plant structures, systems and components subjected to a variety of age-related degradation mechanisms (Grizzly) and the RELAP-series of software for thermal-hydraulics (see raven.inl.gov for additional information).

RAVEN has also been used for multi-unit risk analysis (for a three-unit plant as shown in Figure 24). This analysis used RELAP5-3D and performed probablistic scenario anlaysis simultaneously with six coupled thermal-hydraulics evaluations (three for the plant cores, three for the spent fuel pools). Specifically, RAVEN was able to drive the analysis for:

- Unit 1: 1 PWR at full power (100\%) and its own spent fuel pool

- Unit 2: 1 PWR in mid-loop operation (i.e., shut-down mode) and its own spent fuel pool. The mid-loop status is characterized by a primary coolant system drained to the hot leg centerline and the existence of openings which a further reduction of the mass inventory poses a serious risk, due to boil off and possible entrainment or spill over of liquid 




Figure 24. Multi-Unit Configuration Schematic.

- Unit 3: A PWR operating at 108\% rated power that restarted a few weeks earlier and its own spent fuel pool with a higher heat load since it contains used fuel recently moved from the reactor.

In addition, Westinghouse has performed scoping dynamic fire risk analysis modeling using the RAVEN code. This modeling activity has successfully evaluated switchgear room fire scenarios using the industry code CFAST by developing a working RAVENCFAST interface and have run thousands of fire simulation scenarios.

\section{External Hazards Modeling}

Risk-informed safety analyses for external events can bring sensible benefits to the nuclear power industry, easing the regulatory burden introduced in the aftermath of the Fukushima accident. In the framework of the RISMC Pathway, research includes developing a toolkit for performing external hazards analysis. This toolkit, EEVE (External EVEnts) is comprised of state-of-the-art codes, including currently available and advanced tools under development.

Risk-informed safety analysis is the most realistic and least conservative safety analysis. It involves the use of Best-Estimate Plus Uncertainty (BEPU) for deterministic calculations and the use of probabilistic risk analysis for determining the availability of systems, structure and components of a nuclear power plant. This results in a more realistic assessment of nuclear power plant safety margins, that reduces or removes undue conservatisms that is reflected in a probabilistic safety assessment with a better characterization of the physical phenomena considered in the scenario. In the RISMC approach, the toolkit has the capability of performing a classical "risk-informed" 
Figure 25. External Events Workflow and EEVE Toolkit.

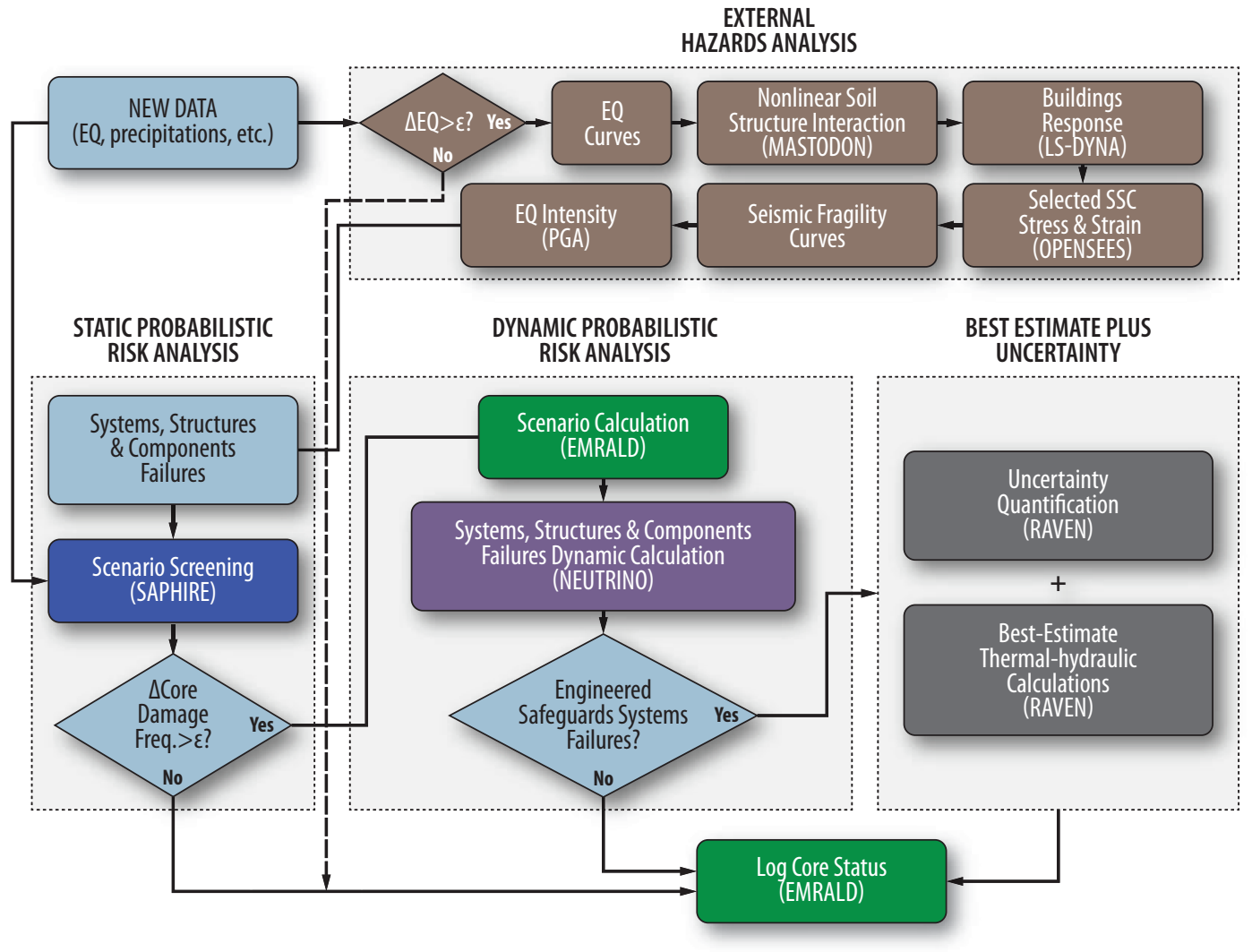

analysis, as well as simulating a "virtual nuclear power plant" replica representation of the plant under consideration. This is achieved by integrating the Best-Estimate (BE) codes in the EEVE toolkit.

The selected codes for the toolkit and the coupling scheme among the codes are shown in Figure 25. Originally, EEVE was established and applied to simulate a pressurized water reactor undergoing a plant transient induced by an earthquake with subsequent internal flooding. EEVE can also be applied to other external hazards such as high winds, intense precipitation, and other classes of external events. EEVE can be used to evaluate new data on external events when relevant studies and data become available, to determine critical areas of a plant's probabilistic risk assessment that would benefit most from advanced analysis methods.

RELAP5-3D is being used as the best estimate code for the system analysis. According to the methodology described in Figure 25, the first step is the deterministic calculations for evaluating the propagation of a set of earthquakes and for ascertaining the effects on a fire suppression system in an auxiliary building. These deterministic calculations are performed using the MASTODON, LS-DYNA and the OPENSEES structural mechanics codes. Their combined use allows the safety analyst to calculate the earthquake propagation in the soil (MASTODON), the building and the systems response to the earthquake shaking (LS-DYNA and OPENSEES), see Figure 26.

The second step is to evaluate the probability of failures and resulting event trees of a generic 3-loop Westinghouse PWR, derived from a generic SAPHIRE probabilistic 


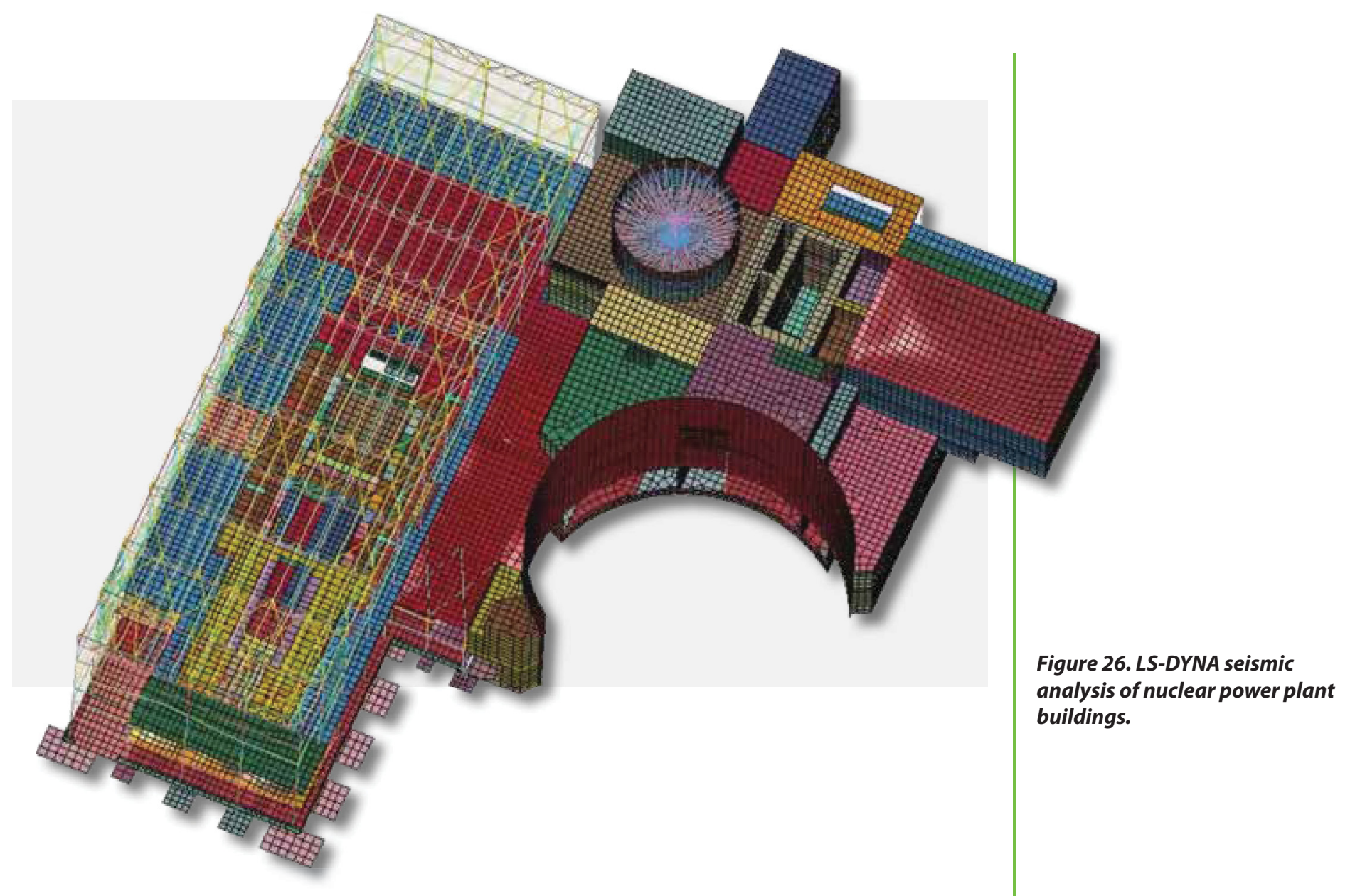

risk-analysis code model. Events considered are seismically induced loss of offsite power, station blackout, and fire suppression piping failure. The SAPHIRE code allows pre-screening of all possible branches of the event trees and selection of those with the largest core damage frequency increase for further analysis using dynamic probabilistic risk-analysis methods.

If the change in the core damage frequency exceeds some threshold, the third step is taken. The RISMC Pathway's Event Model Risk Assessment Linked Diagrams (EMRALD) code performs dynamic probabilistic risk-analysis calculations of the identified sequences. It integrates risk analysis with on-line deterministic safety analysis results from seismically-induced internal flooding calculations from the NEUTRINO code, combined with Best-Estimate Plus Uncertainty (BEPU) analyses by RELAP5-3D-RAVEN coupled codes. NEUTRINO is a three-dimensional code which can simulate flooding scenarios of compartments, rooms, open fields, etc. (see Figure 27).

If NEUTRINO finds that the flooding affects some of the Engineered Safeguard Systems, EMRALD invokes RELAP5-3D/RAVEN system calculation for further analysis of the scenario. Otherwise, EMRALD logs the outcome of NEUTRINO calculations as a "safe" status for the reactor core.

Risk-informed safety analysis involves the use of BEPU technology. Therefore, RELAP5$3 \mathrm{D}$ is coupled with RAVEN uncertainty code to provide BEPU calculations to EMRALD. 
Figure 27. NEUTRINO Flooding Simulation.

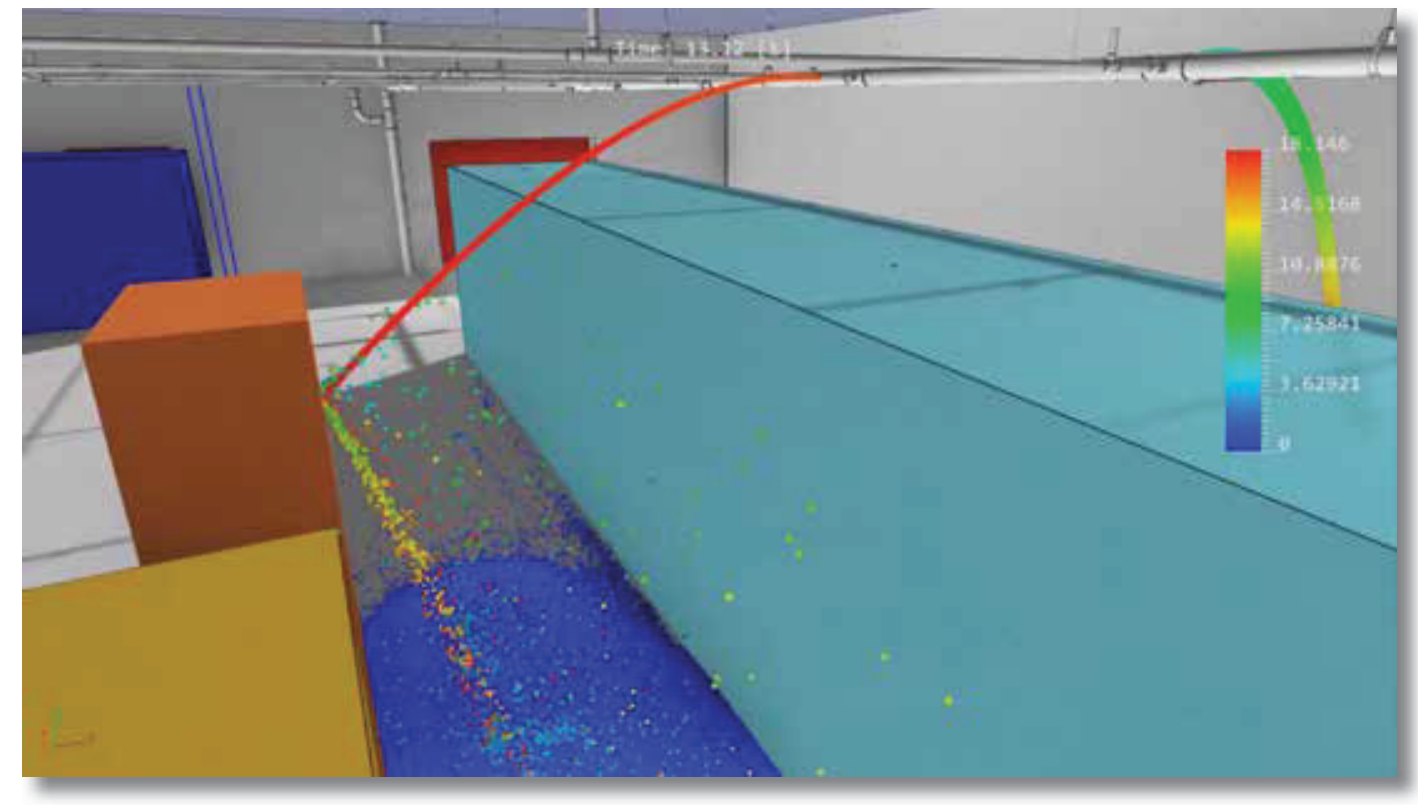

RELAP5-3D/RAVEN coupled codes are invoked by EMRALD if Engineered Safeguard Systems fail because of damaging flooding conditions calculated by NEUTRINO. RELAP5-3D is run using a 3-loop Westinghouse PWR nodalization for the different loss of offsite power and station blackout scenarios.

Monte Carlo based perturbations of a given disturbance scenario can be run by RAVEN, providing users the capability to use RAVEN to direct the activities of many automated simulations of a simulated plant transient in order to calculate a distribution of outcomes of key plant parameters. For one example, shown here to highlight this capability, first and fourth order statistics have been obtained from a large number of simulations of two plant disturbances (loss of offsite power and station blackout) demonstrating the coupled codes capabilities. This entailed running 59 and 153 Monte Carlo simulations, respectively, for each of these scenarios using RELAP5-3D, and using RAVEN to perturb input uncertainty parameters. An example of the results of these calculations is shown in Figure 28, which shows the uncertainty ranges for a key plant parameter - cladding temperature - modeled from a number of Monte Carlo simulations for a loss of offsite power simulated event. The value of this approach is that, in contrast to current approaches that produce a point estimate for a key plant parameter such as clad temperature during the simulated plant transient, RAVEN's coupling with a state of the art systems code enables multiple simulations and uncertainty calculations to be made with resulting uncertainty estimates of key plant parameters. This enables post-hoc analyses of the results to be performed to understand sensitivities in the analyses and determine contributors to the outcomes that influence the resulting risk or consequence to the plant parameters - yielding valuable insights into key system contributors to risk and potential plant-specific mitigation approaches.

RAVEN has also been used to automatically produce a limit surface search for loss of offsite power and station blackout scenarios. A limit surface is an $\mathrm{n}$-dimensional 


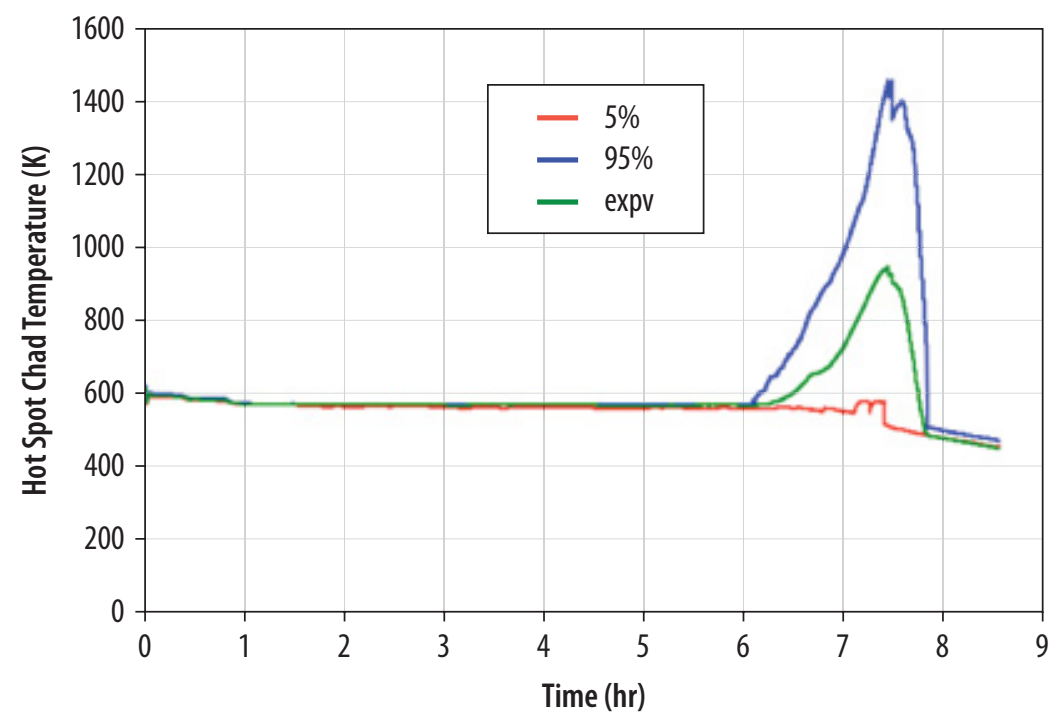

surface describing the plant status on the basis of scenario failure or success (e.g., safe or unsafe) criteria (e.g. identified on the basis of selected plant parameters and the boundaries between failed and safe conditions for the core fuel, for example). Using RELAP5-3D coupled with RAVEN, the RAVEN machine-learning algorithms have been used to identify limit surfaces. Figure 29 shows an example of a limit surface produced by this tool for a simulated station blackout scenario based upon battery failure and crew recovery actions.

The results of RELAP5-3D/RAVEN calculations (BEPU and limit surfaces) are processed by EMRALD, a dynamic probabilistic risk analysis code. EMRALD records the core status for each RELAP5-3D/RAVEN simulation run, using the success and failure criteria defined for system or plant parameters.

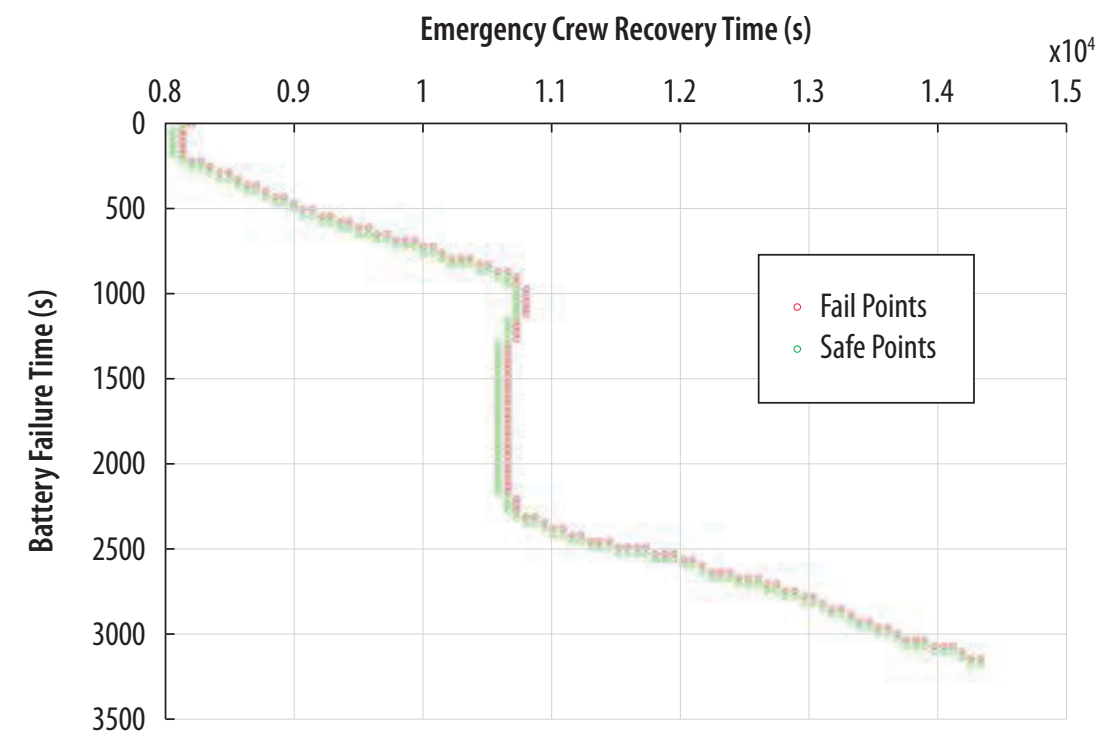

Figure 28. Uncertainty bands for BEPU RELAP5-3D/RAVEN calculation for a loss of offsite power scenario.
Figure 29. RELAP5-3D/RAVEN limit surface for station blackout scenario. 
Collectively, these family of codes and their unique capabilities to operate in a seamless framework enable the estimation of a number of important plant and risk-significant parameters needed to address external events in probabilistic risk assessments. They provide strong coupling between codes and the ability to simulate risk-important events in a manner previously unavailable to plants and risk analysis professionals. They represent significant advances in the fidelity of modeling and simulation technology available for risk analysis that can improve both the realism in analysis and reduce conservatisms, enabling the analysis of factors that are of greatest sensitivity and drive plant-specific results to yield greater insights for better plantspecific approaches to safety margin management.

\section{LOTUS - A Multi-Physics Best Estimate Plus Uncertainty (MP-BEPU) Analysis Framework}

In 2017 the RISMC Pathway collaborated with Texas A\&M University to produce a generic pressurized water reactor (PWR) model including reactor core, clad/fuel design and systems thermal-hydraulics based on the South Texas Project plant (Figure 30), a 4-Loop Westinghouse PWR. A Multi-Physics Best Estimate Plus Uncertainty (MP-BEPU) analysis framework, named loss of coolant accident (LOCA) Toolkit for the U.S. (LOTUS), has been developed for use in this generic PWR plant model to assess safety margins for the proposed U.S. Nuclear Regulatory Commission 10 CFR 50.46c rule, Emergency Core Cooling System performance during LOCA.

This demonstration includes coupled analysis of core design, fuel design, thermalhydraulics and systems analysis, using advanced RISMC developed risk analysis tools and methods to investigate a wide range of results. The set of modeled results shows that peak clad temperature and fuel cladding oxidation responses (measured by equivalent cladding reacted) are well characterized by performance based modeling under large break LOCA conditions. Both peak clad temperature and fuel cladding oxidation responses (measured by equivalent cladding reacted) comply with a U.S. Nuclear Regulatory Commission-proposed acceptance criteria with sufficient margins available. Furthermore, these demonstration calculations indicate the importance of safety margin management and planning for future operating cycles. Since nuclear fuel stays in a reactor for multiple operating cycles, planning of loading and operating strategies needs to be well thought out.

The intrinsic value of successful research and development for the proposed LOTUS framework is expected to be significant. LOTUS has the potential of becoming a powerful safety margin management tool for industry stakeholders to address the challenges imposed by the emerging issues such as plant equipment upgrades to support the implementation of FLEX, additional new passive cooling systems, improved operational control, accident-tolerant instrumentation, and to gain potential benefits from 50.69 safety significance reclassification by relying on a more rigorous mathematical and physics-based apparatus to address model and data uncertainty in safety analysis.

The importance of the LOTUS framework also extends to current and future nuclear fuels development and applications. The progress shown this year on the LOTUS development and application is a step forward towards modeling and simulation predictive capability, and it can provide useful tools for the development and 


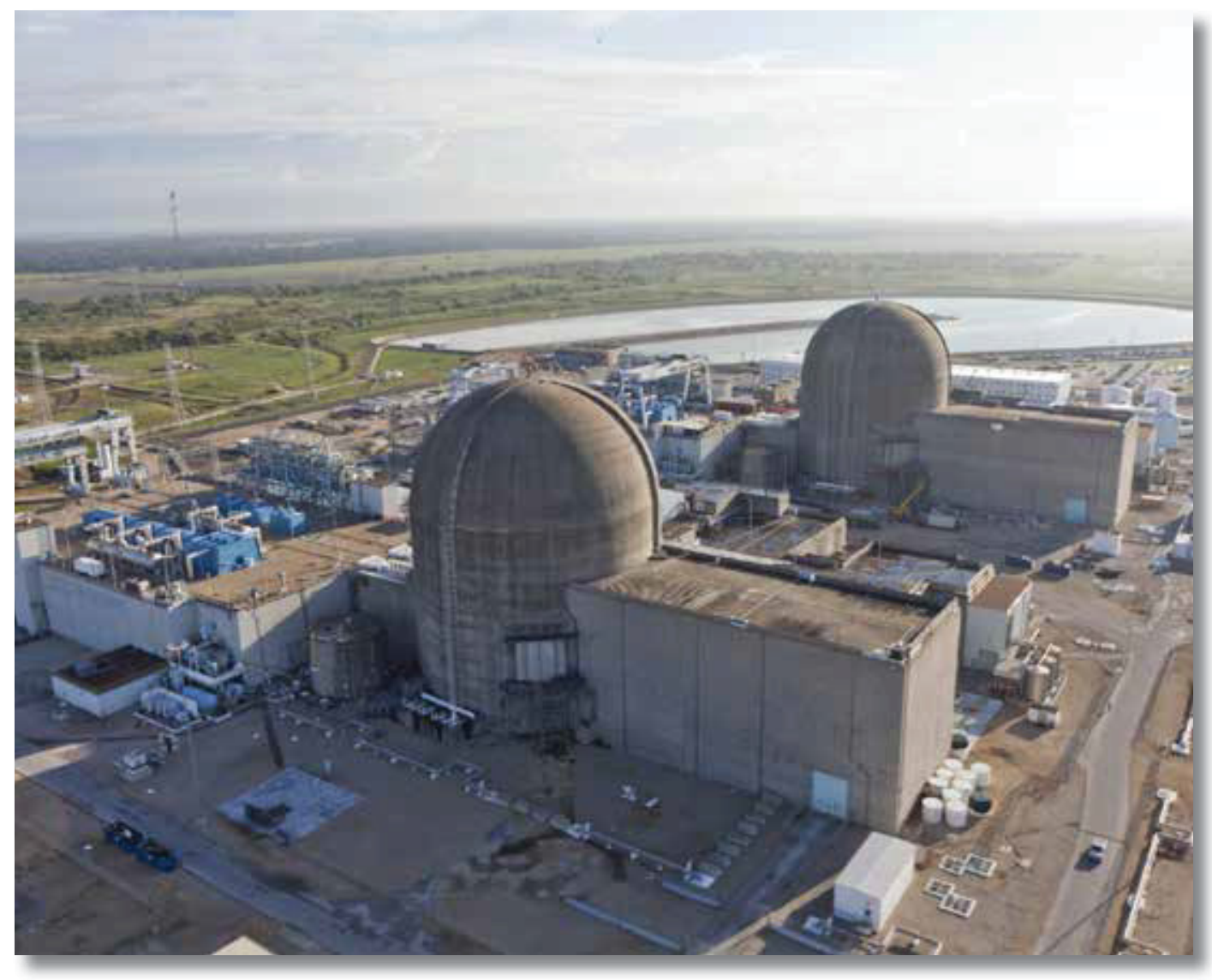

Figure 30. South Texas Project Nuclear Units.

characterization of accident tolerant fuels, a joint program pursued by DOE and the nuclear industry. Accident tolerant fuels could have "game changing" attributes to transform the nuclear industry. Having an integrated multi-physics toolkit that is fuel/ clad-, fuel cycle-, and scenario-centric provides a ready platform for the analysis of novel fuel and cladding systems. The coupled multi-physics, multi-scale LOTUS analysis framework allows plant system configuration variations to be studied with speed and precision, including detailed assessment of introducing accident tolerant fuels into current LWR plants for design enhancements. This evaluation approach becomes important when analyzing magnitude range and timeline of system response for relevant sequence of events. 


\section{Reactor Safety Technologies}

T he Reactor Safety Technologies Pathway is carrying out research and development efforts to improve understanding of beyond design basis events and reduce uncertainty in severe accident progression, phenomenology, and outcomes using existing analytical codes and information gleaned from severe accidents, in particular the March 2011 events at Fukushima Daiichi. This information will be used by industry to aid in developing mitigating strategies and improving severe accident management guidelines for the current light water reactor fleet.

\section{Research Highlights}

Select research and development highlights are provide here. Detailed reports covering the accomplishments can be found on the LWRS Program website (https:// Iwrs.inl.gov).

\section{MAAP-MELCOR Crosswalk Phase II}

Phase 2 of the MAAP-MELCOR crosswalk was completed. This work was a collaboration between the LWRS Program, Sandia National Laboratories, Electric Power Research Institute, and the U.S. Nuclear Regulatory Commission which aimed to determine impacts of different core degradation models on a partially recovered accident scenario; similar to the one that occurred in Three Mile Island-2. In particular, Phase 2 compared the impact of core degradation morphology on quenching models inherent within the two codes and the coolability of debris during partially recovered accidents. These quench and core recovery models are of the most interest when there is a significant amount of core damage, but intact and degraded fuel still remains in the core region or the lower plenum. Accordingly, this analysis presents a spectrum of partially recovered accident scenarios by varying both water injection timing and injection rate to highlight the impact of core degradation phenomena on recovered accident scenarios.

The original (Phase 1) MAAP-MELCOR crosswalk activity was completed in November 2014. This work was motivated by early studies carried out as part of U.S. Department of Energy-funded analyses for Fukushima Daiichi Unit 1 accident. In particular, large

Figure 31. Fuel temperature simulated results using MELCOR and MAAP codes following 1 hour after water injection into a core during a simulated accident progression.

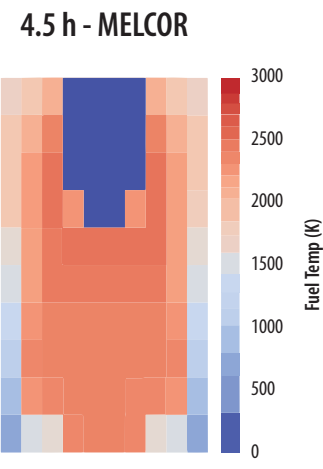

4.5 h - MELCOR

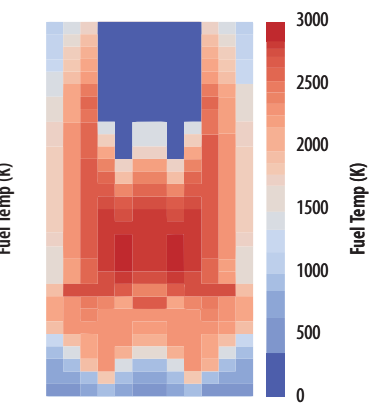

10.00 h - MAAP

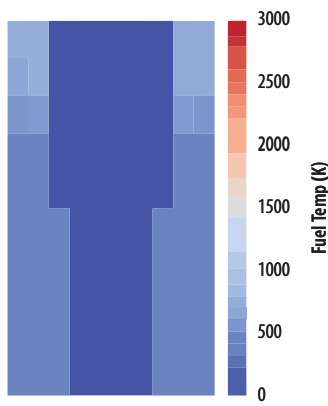

10.00 h - MAAP

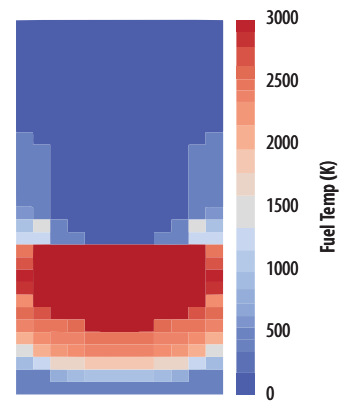


differences were observed between the two codes regarding the prediction of the accident progression and, correspondingly, safety-significant phenomena (i.e., extent of hydrogen production). This result was not expected as the Unit 1 accident sequence was relatively simple (i.e., an unmitigated station blackout). The crosswalk activity was thus initiated to identify essential modeling differences between the two codes leading to the divergence in predictions as a basis for formulating research and development to resolve the differences. The key modeling difference/uncertainty was found to be the degree that core debris retains interconnected porosity during the latter stages of in-core melt progression. Resolution of this uncertainty is important as these codes are used for plant safety assessments as well as tools supporting training of plant operators on severe accident management procedures.

In summary, the results of the Phase 2 analysis indicate continued differences between the two codes in the long-term coolability and recoverability of damaged cores (see Figure 31). These differences can be traced back to the representation and progression of fuel degradation in the early stages of the core degradation as identified in the Phase 1 study. These differences in core degradation representation can have real consequences for operators developing drills that are made to realistically represent the plant behavior during a severe accident.

\section{Terry Turbine Testing and Analysis}

All boiling water reactor (BWR) reactor core isolation cooling (RCIC) systems and pressurized water reactor (PWR) auxiliary feed water systems use Terry turbines in their safety systems (Figure 32). Prior to the accidents at the Fukushima Daiichi nuclear reactor site, assumptions and modeling of the
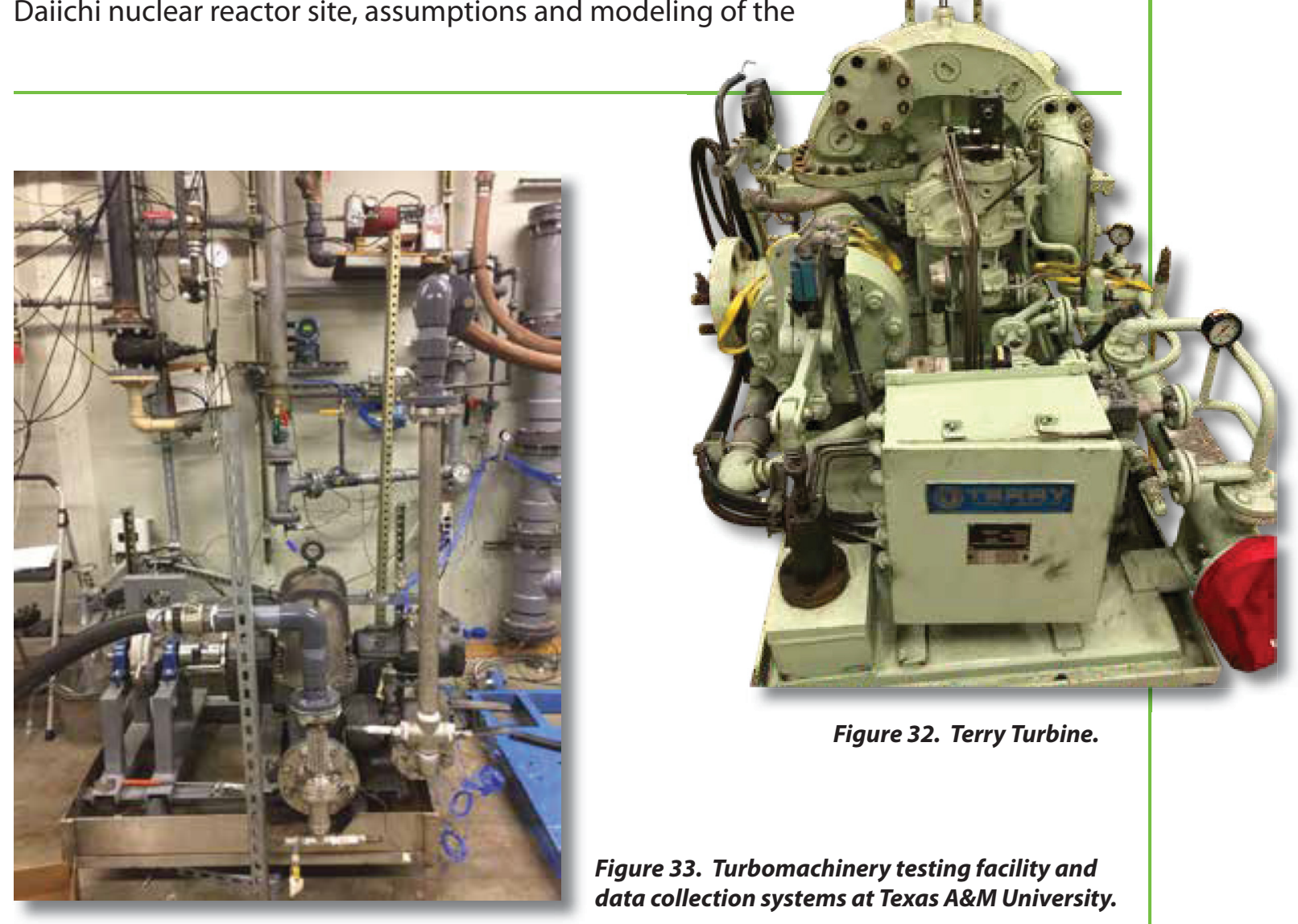

Figure 32. Terry Turbine.

Figure 33. Turbomachinery testing facility and data collection systems at Texas A\&M University. 
performance of Terry turbopumps were based mostly on generic design basis conditions. The RCIC System performance under beyond design basis event conditions was poorly known and largely based on conservative assumptions used in probabilistic risk assessment applications. However, in two of the Fukushima Daiichi accidents, the RCIC System operated well beyond expectations in a "self-regulating" mode and it is now thought to have far greater ability to remove core heat under beyond design basis event conditions than previously believed.

As part of the efforts to understand the unexpected "self-regulating" operational mode of the RCIC systems observed during Fukushima accidents and to extend BWR RCIC and PWR turbine-driven auxiliary feed water operational range and flexibility, mechanistic models for Terry turbine performance are being developed and validated as part of a collaborative research and development program involving Japan (Institute of Applied Energy), U.S. industry (BWR owners group and Electric Power Research Institute), and the national laboratories (i.e., Idaho National Laboratory and Sandia National Laboratories). Models for extended RCIC performance have been developed and implemented into thermal-hydraulics code to simulate the RCIC system.

The mechanistic models are able to predict the steam mass flow rate and supersonic velocity to the Terry turbine bucket entrance, which are the necessary input information for the Terry turbine rotor model. An input model was also developed to validate the RCIC system performance predictions under the normal operation conditions. An extension to the single-phase analytical Terry turbine model to cover two-phase off-design conditions. A new two-phase Terry turbine model was also benchmarked with the same steam nozzle tests as for the single-phase model. A new RCIC system test case has been developed to simulate the self-regulated Terry turbine behavior observed in Fukushima accidents.

Complementary efforts are also underway at Sandia National Laboratories to support MELCOR modeling enhancements for Terry turbine driven systems for both PWRs and BWRs. In addition, a test program to investigate $\mathrm{RCIC}$ performance under beyond design basis operating conditions was initiated in 2017 at Texas A\&M University (Figure 33); data from these tests will be used to validate the enhanced models.

\section{Ex-Vessel Coolability and Water Management}

The U.S. Nuclear Regulatory Commission Severe Accident Capable Vent Order EA13-09 requires licensees with Mark I and Mark II containments to upgrade or replace reliable hardened vents with a containment venting system designed and installed to remain functional during severe accident conditions. To satisfy this order, industry is pursuing a severe accident water management strategy as an alternative to installing filters on the vents. In particular, industry is developing water addition strategies that will achieve the accident management objectives of keeping ex-vessel core debris covered and cooled by water, while maintaining the containment vent path through the suppression pool (Figure 34).

To support this effort, melt spreading (i.e., MELTSPREAD) and debris coolability (i.e., CORQUENCH) models are being developed at Argonne National Laboratory and Oak Ridge National Laboratory to support industry efforts in the development of severe accident water management strategies. The specific objective of this work is to provide a validated set of tools for use by industry in optimizing containment 

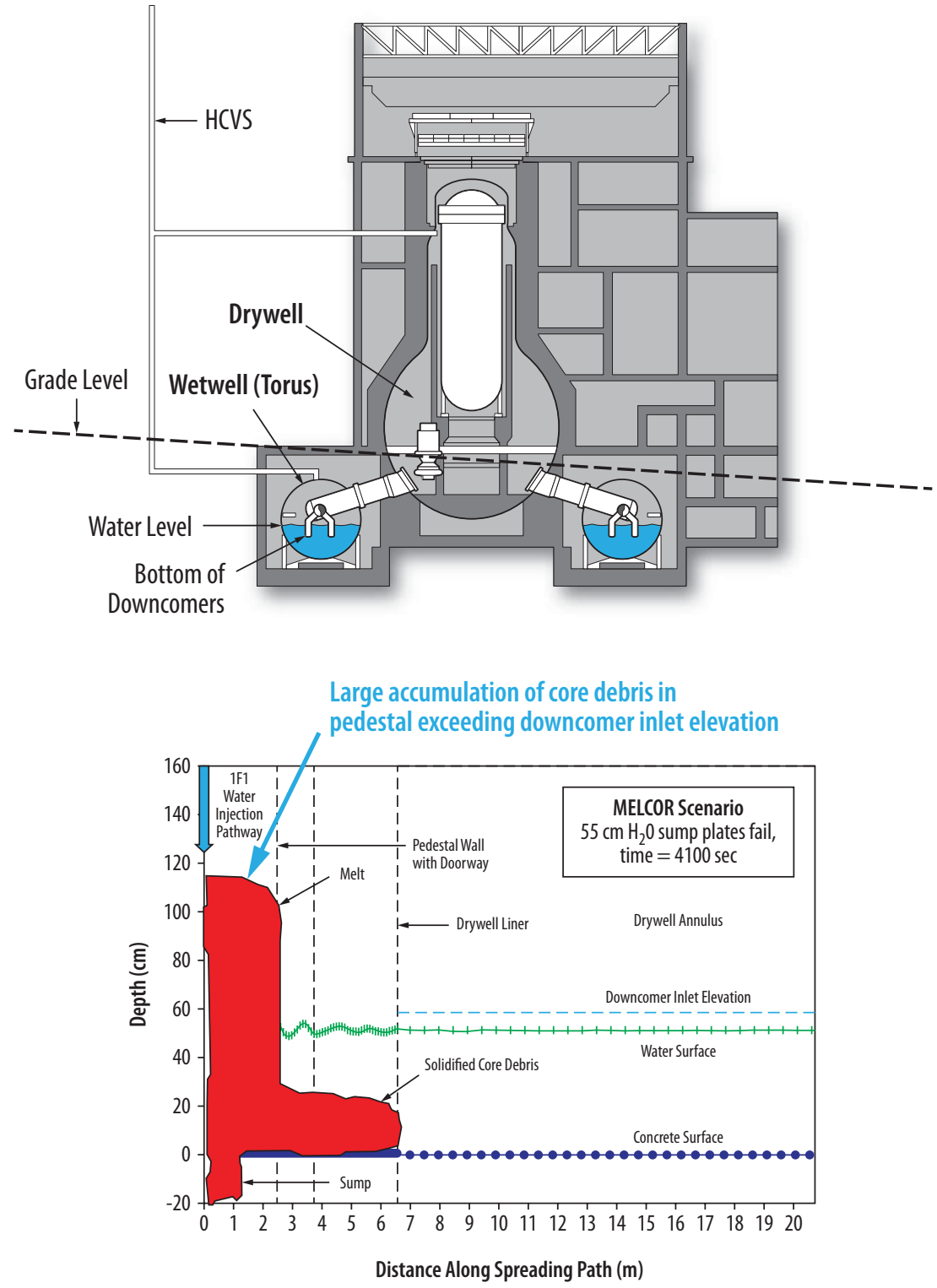

flooding rate and injection pathway that achieves core debris cooling while preserving wetwell vent path. As part of this work, large scale integral debris coolability tests are being conducted to provide model validation data as part of a collaboration led by Électricité de France that includes U.S. Department of Energy, U.S. Nuclear Regulatory Commission, IRSN, and CEA. In 2017 the ex-vessel debris coolability experiment was successfully conducted and documented in support of CORQUENCH validation. This was a large-scale test investigating the water ingression cooling mechanism for prototypic core debris interacting with a siliceous concrete basemat. This concrete type is typical of many plants in the United States, Europe, and Asia.

In 2017 beta versions of the upgraded MELTSPREAD (Figure 35)and CORQUENCH models were provided to Electric Power Research Institute who is using these codes to carry out initial assessments of severe accident water management strategies. Based on user feedback, the models will be updated and a final version released at the end of 2018 .
Figure 34. Side view of a Boiling Water Reactor, containment, and associated systems being used to develop water addition strategies for severe accident management.

Figure 35. MELTSPREAD simulation of core debris and related system performance metrics produced through severe accident research sponsored by the LWRS program. 


\section{PROGRAM CONTACTS}

\section{Program Management}

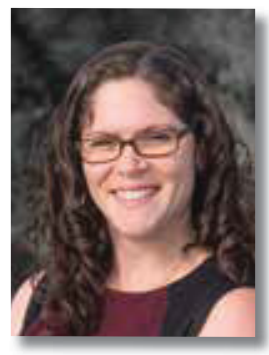

\section{Alison Hahn}

Federal Program Manager

Office of Nuclear Energy

U.S. Department of Energy

alison.hahn@nuclear.energy.gov

(301) 903-5049

\section{Technical Integration Office}

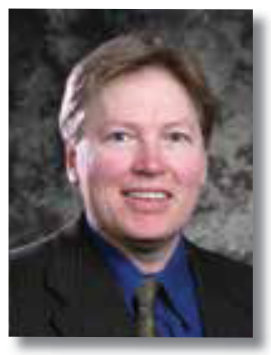

\section{Bruce P. Hallbert}

Director

Idaho National Laboratory

bruce.hallbert@inl.gov

(208) 526-9867

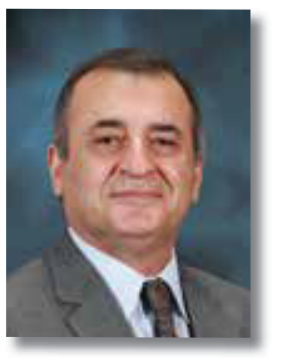

\section{Mehdi Asgari}

Deputy Director

Oak Ridge National Laboratory

asgarim@ornl.gov

(865) 576-4467

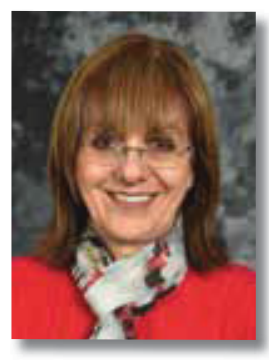

\section{Cathy J. Barnard}

Operations Manager

Idaho National Laboratory

cathy.barnard@inl.gov

(208) 526-0382

"I believe the future of nuclear energy in the United States is bright and look forward to expanding American leadership in innovative nuclear technologies."

- $\quad$ Rick Perry

U.S. Secretary of Energy 


\section{Research and Development Pathway Leads}



\section{Materials Aging and Degradation}

Keith J. Leonard

Oak Ridge National Laboratory

leonardk@ornl.gov

(865) 576-3687

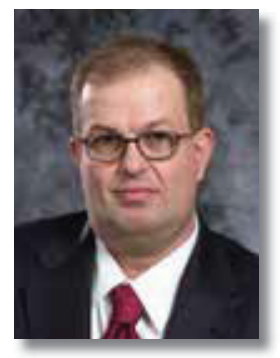

Risk-informed Safety Margin Characterization

Ronaldo H. Szilard

Idaho National Laboratory

ronaldo.szilard@inl.gov

(208) 526-2930

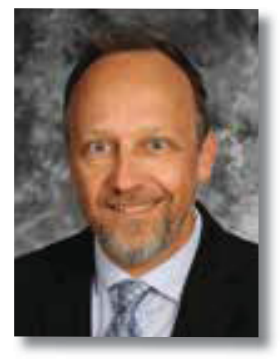

Advanced Instrumentation, Information \& Control Systems Technologies

\section{Craig A. Primer}

Idaho National Laboratory

craig.primer@inl.gov

(208) 526-0446

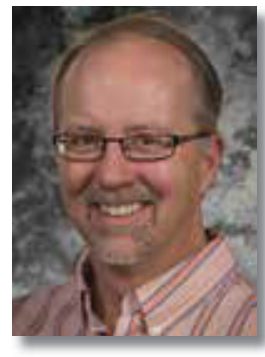

\section{Reactor Safety Technologies}

Mitchell T. Farmer

Argonne National Laboratory

farmer@anl.gov

(630) 252-4539

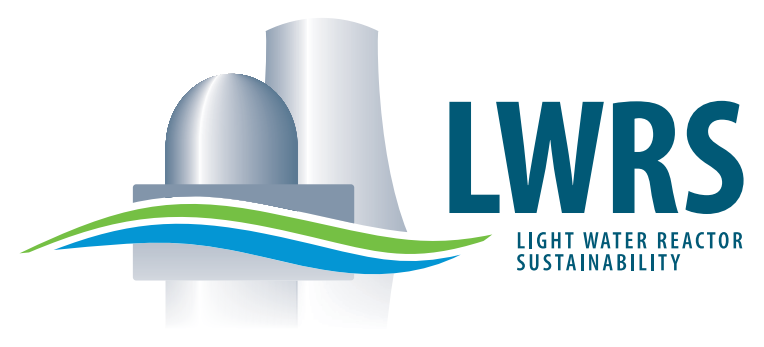




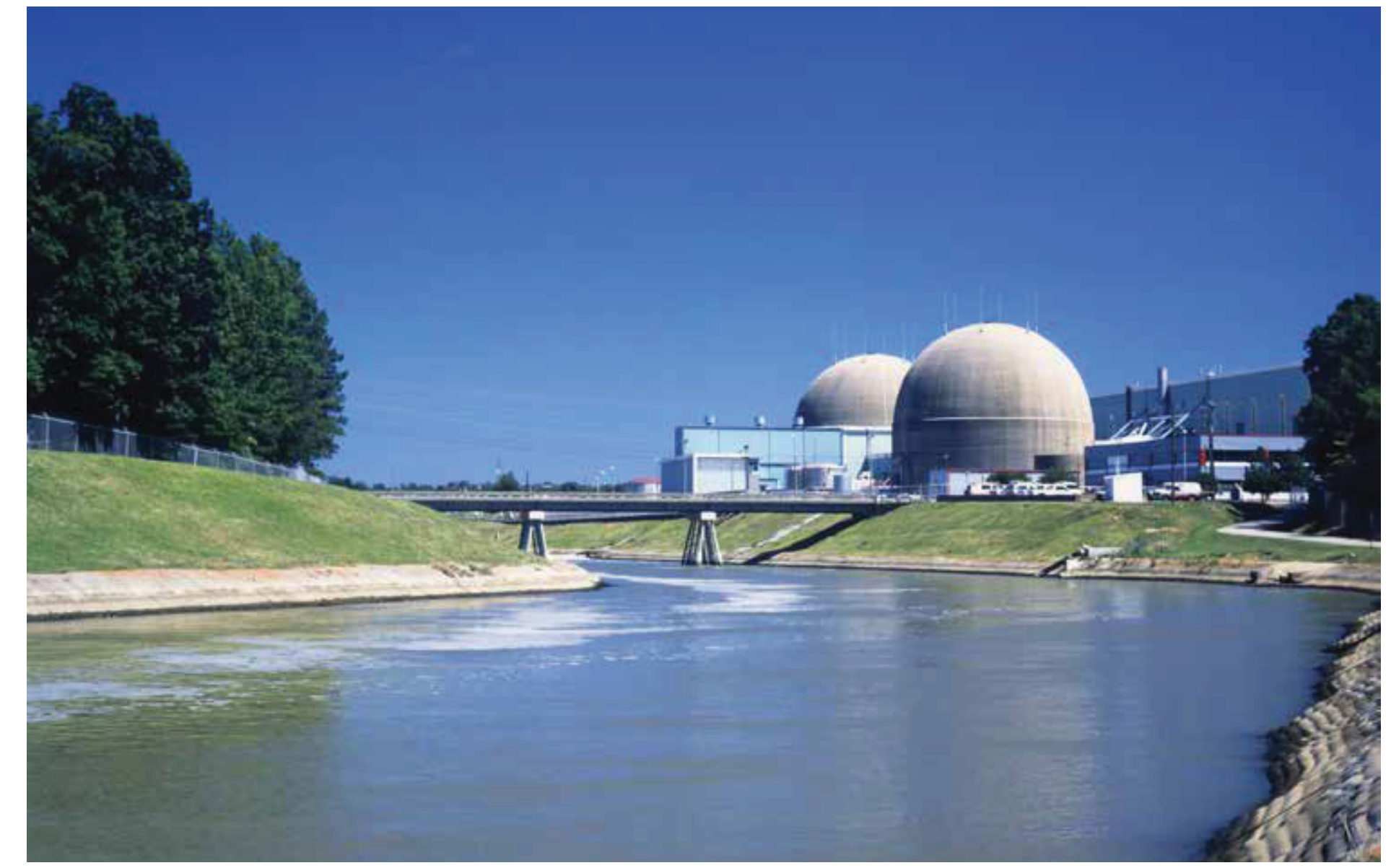

In November 2015, Dominion was the first company to announce its intent to seek a second license renewal for its Surry Power Station in Virginia, formally initiating the next round of plans for plant license extensions in the United States. The LWRS Program conducts research and development to provide the technical basis for second license renewal specifically, and long-term operation generally. 